\title{
Microwave Combustion and Sintering Without Isostatic Pressure
}

\author{
Topical Report \\ August 1, 1995 - October 30, 1996 \\ By: \\ M. A. Ebadian \\ N. D. H. Monroe
}

Work Performed Under Contract No.: DE-FG21-95EW55094

For

U.S. Department of Energy

Office of Fossil Energy

Federal Energy Technology Center

P.O. Box 880

Morgantown, West Virginia 26507-0880

By

Florida International University

Hemispheric Center for Environmental Technology (HCET)

Center for Engineering \& Applied Sciences

10555 West Flagler Street

EAS-2100

Miami, Florida 33174 


\section{Disclaimer}

This report was prepared as an account of work sponsored by an agency of the United States Government. Neither the United States Government nor any agency thereof, nor any of their employees, makes any warranty, express or implied, or assumes any legal liability or responsibility for the accuracy, completeness, or usefulness of any information, apparatus, product, or process disclosed, or represents that its use would not infringe privately owed rights. Reference herein to any specific commercial product, process, or service by trade name, trademark, manufacturer, or otherwise does not necessarily constitute or imply its endorsement, recommendation, or favoring by the United States Government or any agency thereof. The views and opinions of authors expressed herein do not necessarily state or reflect those of the United States Government or any agency thereof. 


\section{DISCLAIMER}

Portions of this document may be illegible in electronic image products. Images are produced from the best available original document. 


\section{TABLE OF CONTENTS}

LIST OF FIGURES $\mathrm{v}$

LIST OF TABLES. .

NOMENCLATURE vi

1. INTRODUCTION

1.1 BACKGROUND OF THE PROBLEM..

1.2 PURPOSE OF THIS INVESTIGATION 1

1.3 LITERATURE REVIEW 2

2. PROJECT DESCRIPTION. . .2

2.1 OVERALL PROJECT GOALS. 6

2.2 FY96 ACTIVITIES 6

2.3 FY97 OBJECTIVES 6

3. PROCESS DESCRIPTION .7 8

3.1 FUNDAMENTAL CONCEPTS AND THEORIES .......................................................

3.2 SAFETY AND REGULATORY CONCERNS.............................................................

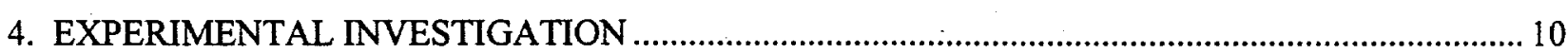

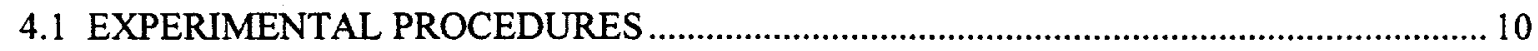

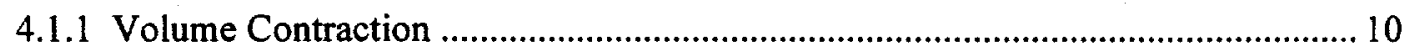

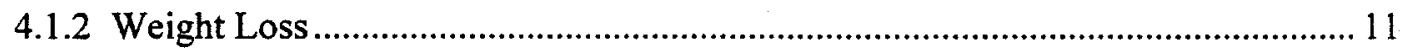

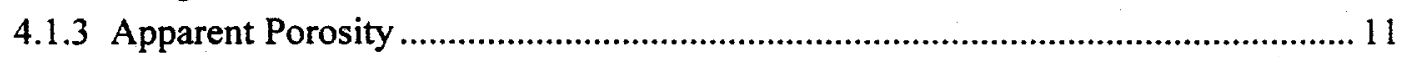

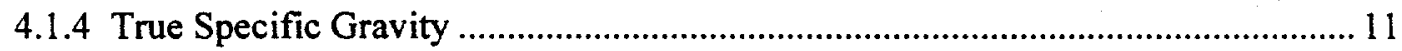

4.2 MICROSTRUCTURE OBSERVATION AND ANALYSIS (SEM AND EDAX).

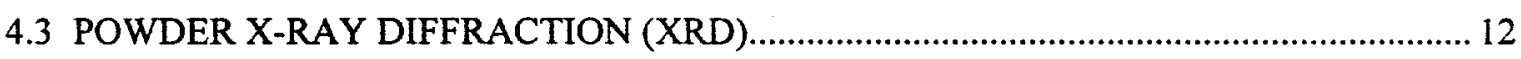

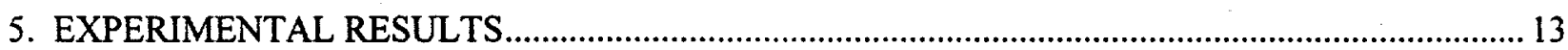

5.1 CHARACTERIZATION OF THE STARTING MATERIALS ........................................ 13

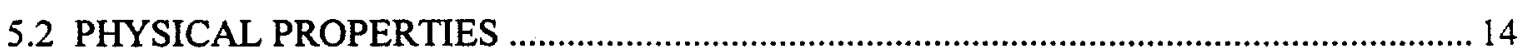

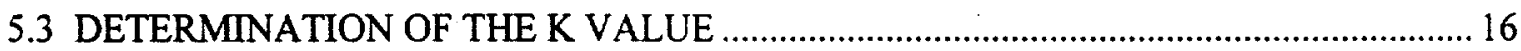

5.3.1 K Value of the Reference Materials ............................................................... 17

5.4 PHASE FRACTION IN THE MIXTURE OF THE SINTERED PELLETS ......................... 18

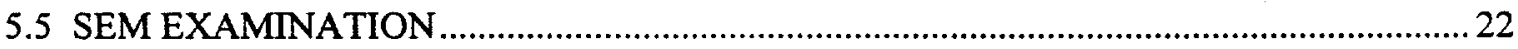

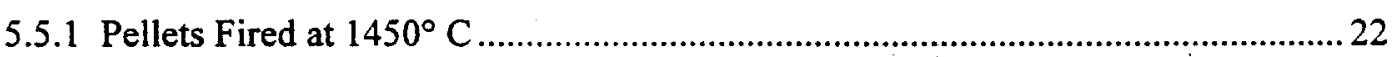

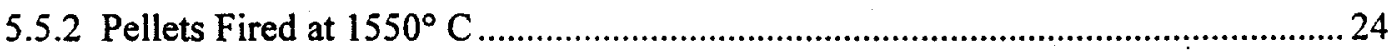

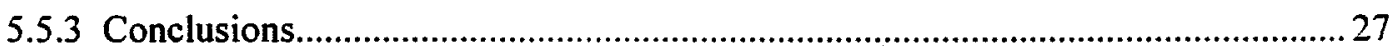

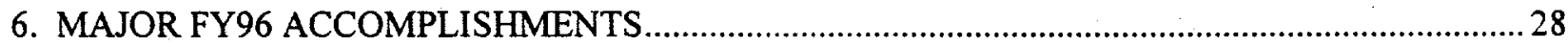

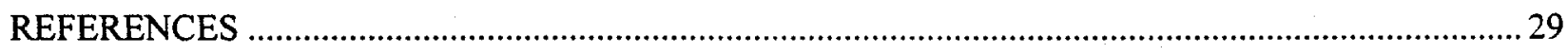

APPENDIX 



\section{LIST OF FIGURES}

Figure i. Schematic diagram of a variabie frequency microwave furnace.

Figure 2. Diamond deposition with controlled fixed frequency @ 7.4 Ghz with 200 watts at 20 torr vacuum.

Figure 3. Mineralogical composition of starting material.

Figure 4. Apparent porosity upon sintering of bauxite materials.

Figure 5. Specific gravity upon sintering of bauxite material.

Figure 6. Volume contraction upon sintering of bauxite material.

Figure 7. Weight loss upon sintering of bauxite material.

Figure 8. Powder X-ray diffraction pattern of (a) raw bauxite, (b) traditional bauxite, (c) tailing pond material, (d) capping material fired at $1450^{\circ}, 1550^{\circ}, 1650^{\circ}$, and $1750^{\circ} \mathrm{C}$. A denotes corundum; $\mathrm{M}$, mullite; $\mathrm{C}$, cristobalite; and $\mathrm{F}$, fluorite.

Figure 9. Weight percent of mullite upon sintering of bauxite material.

Figure 10. Weight percent of corundum upon sintering of bauxite material.

Figure 11. Corundum in the pore and $\mathrm{Fe}_{2} \mathrm{O}_{3}$ segregation, traditional bauxite, $1450^{\circ} \mathrm{C}$.

Figure 12. Segregation of impurities in pores and isolated particle of cristobalite, tailing pond material, $1450^{\circ} \mathrm{C}$.

Figure 13. Surface layer of the raw bauxite, $1550^{\circ} \mathrm{C}$.

Figure 14. Two layers in the traditional bauxite, $1550^{\circ} \mathrm{C}$.

Figure 15. Corundum particle and segregated impurities in the surface layer, traditional bauxite, $1550^{\circ} \mathrm{C}$.

Figure 16. Complex morphology within a pore in the surface layer, tailing pond material, $1550^{\circ} \mathrm{C}$.

Figure 17. Two layers in the capping material, $1550^{\circ} \mathrm{C}$.

\section{LIST OF TABLES}

Table 1. Composition of Starting Bauxite Materials

Table 2. $K$ Value Determined from the Synthetic Mixtures 
$T_{\text {ig }} \quad$ Ignition temperature of combustion synthesis $(\mathrm{K})$

$T_{c} \quad$ Maximum or combustion temperature during combustion synthesis $(K)$

n Reaction stoichiometry coefficients

$\mathrm{C}_{\mathrm{p}}\left(\mathrm{R}_{\mathrm{i}}\right) \quad$ Heat capacities of reactant $\mathrm{R}_{\mathrm{i}}(\mathrm{J} / \mathrm{mol} \cdot \mathrm{K})$

$\mathrm{C}_{\mathrm{p}}(\mathrm{P}) \quad$ Heat capacities for the products $(\mathrm{J} / \mathrm{mol} \cdot \mathrm{K})$

$L\left(R_{i}\right) \quad$ Phase transformation enthalpies (if the reactant undergoes a phase change such as melting) of reactant $R_{i}(J)$

$\mathrm{L}\left(\mathrm{P}_{\mathrm{j}}\right) \quad$ Phase transformation enthalpies (if the product undergoes a phase change) for the . products (J)

$\mathrm{H}(\mathrm{R}) \quad$ Amount of heat needed to ignite the exothermic reaction $(J)$

$\mathrm{H}(\mathrm{P}) \quad$ Amount of heat available for absorption by the products under adiabatic conditions $(J)$

$\Delta \mathrm{H}_{(298)} \quad$ Reaction enthalpy at $298 \mathrm{~K}(\mathrm{~J})$

$\Delta \mathrm{H}\left(\mathrm{T}_{\mathrm{ig}}\right) \quad$ Heat of reaction $(\mathrm{J})$

$\varepsilon^{*} \quad$ Material's complex permittivity $(\mathrm{F} / \mathrm{m})$

$\varepsilon^{\prime} \quad$ Dielectric constant

$\varepsilon^{\prime \prime} \quad$ Dielectric loss factor

$\varepsilon_{0} \quad$ Permittivity of free space $(\mathrm{F} / \mathrm{m})$

$\varepsilon_{r^{\prime}} \quad$ Relative dielectric constant

$\varepsilon_{e f f}$ " Effective relative dielectric loss factor

$\tan \delta \quad$ Loss tangent

$\sigma$

$f \quad$ Frequency of applied microwave $(\mathrm{GHz})$

$P \quad$ Electromagnetic power absorbed per unit volume of dielectric material $(\mathrm{W} / \mathrm{m})$

E Magnitude of the internal field in the dielectric material $(\mathrm{V} / \mathrm{m})$

S.G. Specific gravity $\left(\mathrm{g} / \mathrm{cm}^{3}\right)$

$K_{i J} \quad$ Coefficient in the expression of X-ray diffraction peak intensity

$\rho_{J} \quad$ Density of the component $\left(\mathrm{g} / \mathrm{cm}^{3}\right)$

$x_{J} \quad$ Weight fraction of the component

$\mu^{*} \quad$ Mass absorption coefficient of the unknown mixture

$x_{S} \quad$ Weight fraction of internal standard components

$x J^{\prime} \quad$ Weight fraction of the unknown after the addition of the internal standard

$K^{J} \quad$ Slope of the calibration curve in the internal standard X-ray method 


\section{INTRODUCTION}

in recent years, interest has grown rapidily in extending the application of microwave energy to the processing of ceramics, composites, polymers, and other materials. Advances in the understanding of microwave/materials interactions will facilitate the production of new ceramic materials with superior mechanical properties. In addition, this understanding will further the development of modern variations of the conventional aluminothermic reaction for joining difficult combinations of ceramics to ceramics, intermetallics, composites, and metals via selfpropagating high-temperature synthesis (SHS). One application of particular interest is the use of microwave energy for the mobilization of uranium for subsequent redeposition.

This investigation is being conducted in four phases, the final phase of which will be devoted to the mobilization and deposition of uranium. Phase I (FY96) consisted of the fundamental sintering of various mixes of ceramic materials to determine the appropriate process conditions. Bauxite extrudates were sintered at various temperatures and analyzed for mineralogical composition by X-ray diffraction (XRD), scanning electron microscopy (SEM), and other analytical tools.

Phase II (FY97) will focus on the determination of the key processing parameters for the sintering of aluminosilicate and other ceramic materials using microwave energy. These materials will be used as matrices for the deposition of radioactive species by a chemical vapor infiltration process. Uranium hexachloride and uranium (IV) borohydride are volatile compounds for which the chemical vapor infiltration procedure might be developed for the treatment of highlevel waste. Microwave heating characterized by an inverse temperature profile within a preformed ceramic matrix will be utilized for chemical vapor infiltration using a carrier gas. Matrix deposition is expected to commence from the inside of the sample where the highest temperature is present. The matrix materials will include alumina-based ceramics, aluminosilicates. and silicon carbide. These materials are all amenable to extreme volume reduction, densification and vitrification. SEM, XRD, and energy dispersive analysis by X-rays (EDAX) will be utilized in the assessment of metal deposition within the matrix.

\subsection{BACKGROUND OF THE PROBLEM}

The conventional surface heating methods for the high-temperature sintering of ceramics developed in the 1960s for the metals industry were characterized by several deficiencies, such as uncontrolled porosity, warping, and microfractures. In recent years, there has been growing interest in the application of microwave energy because of the advantages it offers compared to conventional processing methods. These include clean, rapid, and efficient heating over a wide range of temperatures (up to $2000^{\circ} \mathrm{C}$ or more) as well as new degrees of freedom and flexibility over the conventional methods.

Microwaves are coherent and polarized electromagnetic waves with a frequency range from 300 megahertz $(\mathrm{MHz})$ to 300 gigahertz $(\mathrm{GHz})$, corresponding to wavelengths of 1 meter to 1 millimeter. In the United States, the two most commonly used in industrial ovens are 0.915 and $2.450 \mathrm{GHz}$. The short operating wavelength corresponding to $2.45 \mathrm{GHz}$ is practical for compact 
household ovens. The longer wavelength of $0.915 \mathrm{GHz}$, commonly used in industrial ovens, allows deeper penetration into an object, distributing heat more evenly.

With microwave combustion, ignition commences at the center of the sample, where rapid heating, selective heating, and controllable energy distribution permit greater flexibility for the processing of ceramics. When microwaves penetrate and propagate through a material, the internal electric fields generated within the volume of the material induce translational motion to ionic or molecular dipoles. Resistance to these induced motions results in the heating of the material. In thick sections of ceramic materials (dielectric materials), penetrating radiation creates hot interiors which enable internal moisture and internal gases generated during binder burnout to be removed. Conversely, solid products of reactive gases can be deposited effectively into porous materials during chemical vapor deposition.

In the area of processing advanced materials by microwave energy, a need exists for a greater understanding of microwave/material interactions. The phenomenon commonly known as thermal runaway (in which some materials display increased losses above a critical temperature, leading to a rapid rise in heating) can be beneficial or detrimental under certain circumstances. Under these circumstances, improved kinetics can lead to the production of intermediate vapor transport species that can be advantageous in chemical processing.

\subsection{PURPOSE OF THIS INVESTIGATION}

This investigation involves a study of the influence of key processing parameters on the heating of materials using microwave energy. Selective and localized heating characteristics of microwaves will be utilized in the sintering of ceramics without hydrostatic pressure. In addition, combustion synthesis will be studied for the production of powders, carbides, and nitrides by combining two or more solids or a solid and a gas to form new materials. The insight gained from the interaction of microwaves with various materials will be utilized in the mobilization and subsequent redeposition of uranium.

\subsection{LITERATURE REVIEW}

When microwaves penetrate and propagate through a material, the internal electric fields generated within the volume of the material induce translational motion to ionic or molecular dipoles. Resistance to these induced motions causes losses, attenuating the electric field and volumetrically heating the material (Sutton 1989). The degree of absorption can be quantified by the electromagnetic properties of the material, including electrical conductivity and permittivity and microwave frequency. Consequently, the characterization of dielectric properties is vital to enhancing our understanding of microwave/material interactions.

In the sintering or joining of ceramic materials, rapid heating at high temperatures by combustion synthesis, also known as self-propagating high-temperature synthesis (SHS) or reactive synthesis, (Moore et al. 1994; Munir and Tamburini 1989) is utilized. The self-sustaining, exothermic SHS reaction is initiated at the ignition temperature (Tig). The reaction generates heat that is manifested in a maximum or combustion temperature (Tc) that can exceed $3,000 \mathrm{~K}$. At these temperatures, the melting and volatilization of the reactant and product species facilitate vapor-liquid-solid and vapor-solid transformations that produce structural and property 
modification. If the reaction is triggered by heating only a small portion of the reactant above Tig, the reaction propagates along a moving front in the so-called "propagating mode." If the reaction is triggered throughout the volume of the reactant by heating the entire mass abnve Tig; the reaction occurs in the so-called "simultaneous combustion mode."

The amount of heat, $H(R)$, needed to raise the temperature of the reactants from the initial temperature of the reactants, T0, to Tig and therefore ignite the exothermic reaction in the propagating mode can be represented by:

$$
H(R)=\int_{T_{o}}^{T_{i q}} \Sigma n_{i} C_{p}\left(R_{i}\right) d T+\sum_{T_{0} \sim T_{i q}} n_{i} L\left(R_{i}\right)
$$

where $n_{i}, C_{p}\left(R_{i}\right)$, and $L\left(R_{i}\right)$ are the reaction stoichiometry coefficients, heat capacities, and the phase transformation enthalpies (if the reactants undergoes a phase change such as melting), respectively, of reactant $R_{i}$. The heat of the reaction, $\Delta H\left(T_{i g}\right)$, is expressed by:

$$
\Delta \mathrm{H}\left(\mathrm{T}_{\mathrm{ig}}\right)=-[\mathrm{H}(\mathrm{R})+\mathrm{H}(\mathrm{P})]
$$

and

$$
H(P)=\int_{T_{i g}}^{\operatorname{Tad}\left(T_{0}\right)} \sum n_{j} C_{p}\left(P_{j}\right) d T+\sum_{T_{i g}-T_{24}\left(T_{0}\right)} n_{j} L\left(P_{j}\right)
$$

The amount of heat available for absorption by the products under adiabatic conditions is represented by $H(P)$, which raises the temperature from $T_{i g}$ to the adiabatic temperature, $T_{a d}\left(T_{o}\right)$, where $n_{j}, C_{p}(P)$, and $L\left(P_{j}\right)$ are the reaction stoichiometry coefficients, heat capacities, and phase transformation enthalpies (if the product undergoes a phase change), respectively, for the products, $P_{j}$. Increasing the initial temperature (preheating) from $T_{0}$ to $T_{1}$ decreases $H(R)$, increases $H(P)$ and increases $T_{a d}\left(T_{0}\right)$ to $T_{a d}\left(T_{1}\right)$, assuming that there is no change in $T_{i g}$. Increasing $T_{0}$ to $T_{\mathrm{ig}}$ decreases $H(R)$ to zero, and all of $\Delta H\left(T_{\mathrm{ig}}\right)$ is available for absorption by the products, resulting in an adiabatic temperature of $T_{a d}\left(T_{i g}\right)$. Under these conditions, the reaction is ignited under the simultaneous combustion mode. The heat of the reaction, $\Delta \mathrm{H}\left(\mathrm{T}_{\mathrm{ig}}\right)$, can be calculated as follows:

$$
\begin{aligned}
\Delta H\left(T_{i g}\right)= & \Delta H_{(298)}+\int_{298}^{T_{i g}}\left[\sum n_{j} c_{p}\left(P_{j}\right)-\sum n_{j} c_{p}\left(R_{i}\right)\right] d T \\
& +\left[\sum_{298 \sim T_{i g}} n_{j} L\left(P_{j}\right)-\sum_{298-T_{i g}} n_{i} L\left(R_{i}\right)\right]
\end{aligned}
$$

where $\Delta \mathrm{H}_{(298)}$ denotes the reaction enthalpy at $298 \mathrm{~K}$. Substituting Equations (1), (3), and (4) into Equation (2) and rearranging provides a means by which $T_{a d}$ can be calculated:

$$
\Delta H_{(298)}+\int_{298}^{T_{2 d}} n_{j} C_{p}\left(P_{j}\right) d T+\sum_{298-T_{x d}} n_{j} L\left(P_{j}\right)=0
$$


If heat is lost from the reaction front (i.e., $\Delta \mathrm{Q}$ ), the actual maximum combustion temperature will be $\mathrm{Tc}(\mathrm{To})$.

The microwave processing of materials has traditionally been carried out at fixed frequencies in a furnace at a frequency of 0.915 or $2.45 \mathrm{GHz}$. However, the use of a narrowband microwave source creates limitations on the microwave processing of materials. First, single or narrowband frequency operation results in "hot" and "cold" spots in the microwave cavity. Secondly, frequency restrictions preclude the possibility of optimizing the process to account for frequencydependent material properties. Third, the inability to sweep quickly over a range of frequencies prevents maximization of the heating efficiency to account for temperature-dependent changes in the properties of the materials being processed. Finally, results from fixed-frequency, single- and multimode cavity process developments suffer from the lack of scalability and uniformity control.

Recently, an innovative microwave processing system known as the variable frequency microwave furnace (VFMF) has been developed. The VFMF overcomes the limitations imposed upon microwave processing by conventional methods (Everleigh 1995). This processing system is capable of providing up to $3000 \mathrm{~W}$ of power over an instantaneous frequency bandwidth of up to a full octave spanning the 0.5 to $18.0 \mathrm{GHz}$ frequency range. A schematic structure of the variable frequency microwave furnace is shown in Figure 1.

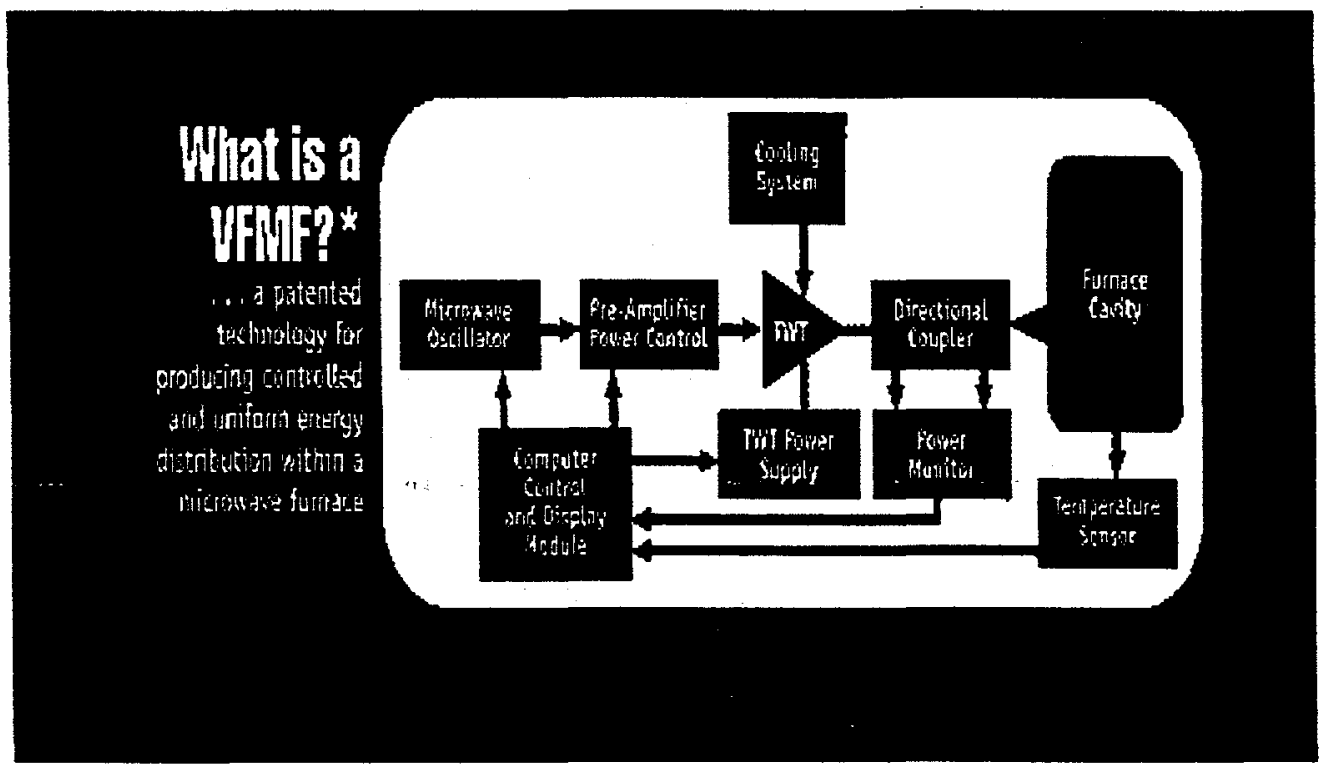

Source: Reprinted from Lambda Technologies, Inc., 1996, Processing with Broadband Irradiation Using the Variable Frequency Microwave Furnace, Lambda Technologies, Raleigh, p. 2.

Figure 1. Schematic diagram of the variable frequency microwave furnace (VFMF).

The microwave furnace is capable of generating localized cylindrical plasma, which enhances chemical vapor deposition for the preparation of thin films. Investigations have demonstrated the utilization of microwave-enhanced plasma to prepare the diamond thin films (Rudder et al. 1993; 
Musil 1996). Figure 2 illustrates three localized plasmas existing just above a substrate surface during diamond chemical vapor deposition. The localized plasmas were projected down the long axis of each cylinder. Each plasma extended for a length of $50 \mathrm{~mm}$.

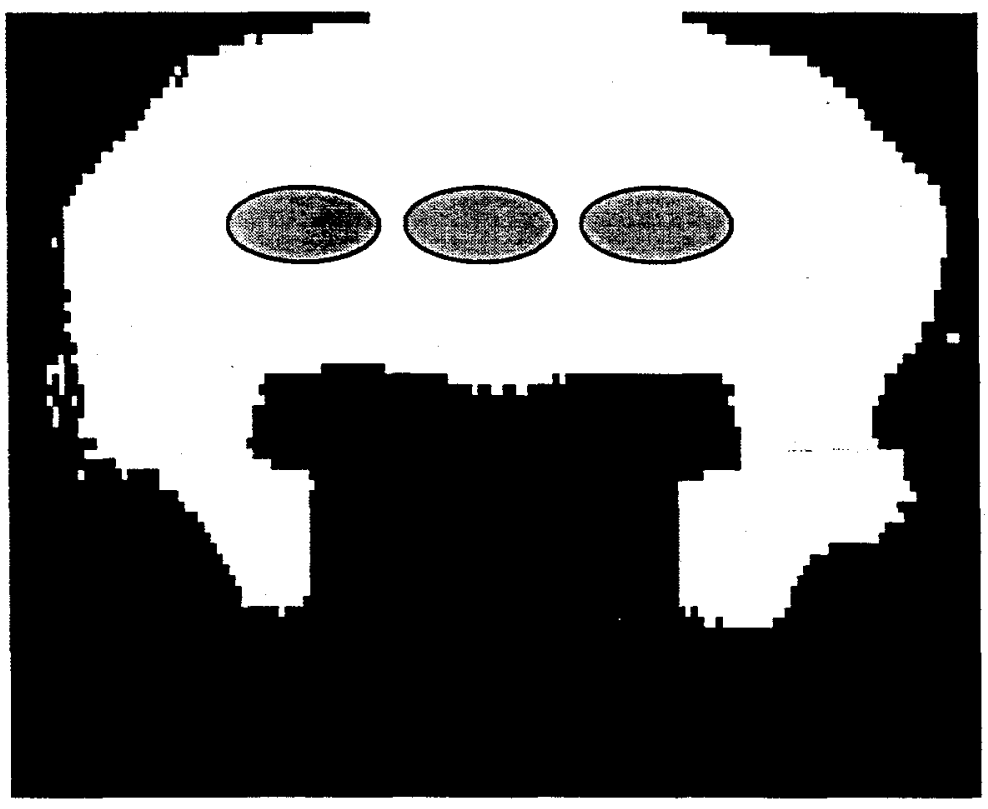

Source: Reprinted, with the permission of the publisher, from R. A. Ruder, R. C. Hendry, G. C. Hudson and R. J. Markunas, 1993, "Diamond Chemical Vapor Deposition via Microwave-Excited Plasma from Water-Ethanol Solutions," Ceramic Transactions, The American Ceramic Society, Vol. 36, p. 377.

Figure 2. Diamond deposition with controlled fixed frequency @ $7.4 \mathrm{GHz}$, with 200 watts, at 20 torr vacuum. 


\section{PROJECT DESCRIPTION}

This project involves the following four phases of investigations of the utilization of microwave energy: 1) sintering of aluminosilicate materials, 2) sintering of matrix materials for chemical vapor infiltration of radioactive materials, 3 ) investigation of microwave-assisted chemical vapor infiltration techniques, and 4) vitrification of the ceramic matrix containing the deposited radioactive species.

\subsection{OVERALL PROJECT GOALS}

Based on the results of investigations on the microwave sintering of ceramic materials, insight into microwave/material interactions and dielectric property behavior at elevated temperatures will be obtained for the development of a microwave-assisted chemical vapor infiltration process for nuclear waste disposal.

In FY96, the appropriate processing parameters for the microwave sintering of aluminosilicate materials were determined. These processing parameters included firing temperature, soaking time, frequency range, frequency sweep rate, and power requirement of the VFMF. The physical properties (porosity, true specific gravity, volume contraction, and weight loss) as well as the mineralogical composition of ceramic materials fired in a microwave furnace were compared to those obtained by firing in conventional furnaces.

The overall project goals for FY97 are:

- To predict the dielectric properties of mixtures and to determine the dielectric constant and loss factor of aluminosilicates and uranyl species as a function of temperature;

- To develop a fundamental understanding of the manner in which the local dielectric permittivity of the ceramic matrix is related to the temperature, density, and microstructure, which change during the process; and

- To provide information which would be useful for the development of microwave technology for waste management applications.

It is expected that the results of this investigation will be useful to the U.S. Department of Energy (DOE) for application in a microwave-assisted chemical vapor infiltration process. This technology can be used for the in-situ remediation of hazardous waste or as a hybrid microwave technology.

\subsection{FY96 ACTIVITIES}

During FY96, various compositions of bauxite materials were blended and extruded into pellets that are referred to as extrudates. The extrudates were sintered at temperatures ranging from $1450^{\circ}$ to $1750^{\circ} \mathrm{C}$ in a graphite-lined furnace under a helium atmosphere. The physical properties of the sintered extrudates, including porosity, true specific gravity, weight loss, volume contraction, and mullite content, were determined. Scanning electron microscopy (SEM) and energy dispersive analysis by X-ray (EDAX) were employed to investigate the microstructure of the sintered extrudates. Photomicrographs were taken of polished cross sections to determine the 
morphology of the sintered materials. Semiquantitative analysis by EDAX was used to identify different phases of the sintered extrudates. The mineralogical composition of the fired samples was quantitatively determined using a powder X-ray diffraction (XRD) analysis method.

FY96 activities included:

- The acquisition of four types of bauxite extrudates - raw bauxite, traditional bauxite, tailing pond material, and capping material - from Guyana Linmine;

- The determination of apparent porosity, specific gravity, volume contraction, and weight loss upon sintering the four types of bauxite extrudates;

- Analysis of the elemental composition and the determination of the mineralogical composition in the raw materials using EDAX;

- Sintering of bauxite extrudates at $1450^{\circ}, 1550^{\circ}, 1650^{\circ}$, and $1750^{\circ} \mathrm{C}$ in a traditional furnace under a helium atmosphere for one and four hours;

- Examination of the morphology of sintered extrudates using scanning electron microscopy (SEM) and the analysis of the elemental composition of micro-areas using energy dispersive analysis by $\mathrm{X}$-rays (EDAX);

- Quantitative determination of the mineralogical composition of sintered extrudates using powder X-ray diffraction analysis; and

- Collaboration with Lambda Technologies for the sintering of extrudates in a variable frequency microwave furnace.

\subsection{FY97 OBJECTIVES}

During FY97, investigations will focus on the following:

- Determination of dielectric properties as a function of temperature. The dielectric constant and loss factor of aluminosilicates and uranyl species as a function of temperature will be determined experimentally as well as acquired by a review of the literature. This will provide the relevant information regarding temperature rise within the matrix materials that will be required in the development of a microwave-assisted chemical vapor infiltration process.

- Microwave firing of preformed matrix materials. Matrix materials composed of aluminosilicates, bauxite, and silicon carbide will be prepared by firing extrudates in a VFMF. The physical properties, mineralogical composition, and microstructures of fired matrix materials will be determined by X-ray diffractometry, scanning electron microscopy, and energy dispersive analysis by X-rays.

- Microwave-assisted chemical vapor infiltration of preformed matrix materials. The various parameters in microwave sintering-frequency, power requirement, soaking temperature, and holding time-will be investigated to determine the optimal conditions for the volatilization of uranyl species using a reactive carrier gas in a microwave chamber. The volatilized uranyl species that is deposited in the ceramic matrix will be vitrified in situ. 


\section{PROCESS DESCRIPTION}

Aithough it is still in an early stage of development, the use of microwave energy to process a wide variety of ceramic materials offers many new and exciting opportunities. There are several reasons for the growing interest in microwave processing versus conventional processing methods. These include the potential for significant reductions in manufacturing costs due to energy savings and shorter processing times, improved product uniformity and yields, improved or unique microstructures and properties, and the synthesis of new materials.

The vitrification of high-level radioactive wastes by microwave energy has been demonstrated on a pilot scale. The evaporation of solutions, the calcination of uranyl salts and radioactive wastes with glass-forming additives, and final vitrification have all been accomplished using microwaves (Suton 1989).

\subsection{FUNDAMENTAL CONCEPTS AND THEORIES}

The efficiency of the microwave heating of a material is determined by the microwave/material interactions (Suton 1989). The degree of interaction (or absorption) of microwave energy by a dielectric material is related to the material's complex permittivity, $\varepsilon^{*}(\mathrm{~F} / \mathrm{m})$, which is composed of a real part ( $\varepsilon^{\prime}$, the dielectric constant) and an imaginary part ( $\varepsilon^{\prime \prime}$, the dielectric loss factor) by

$$
\varepsilon^{*}=\varepsilon^{\prime} j \varepsilon^{\prime \prime}=\varepsilon_{0}\left(\varepsilon_{r^{\prime}}^{\prime} j \varepsilon_{e f f^{\prime \prime}}\right)
$$

where $j$ equals $(-1)^{1 / 2} ; \varepsilon 0$ denotes the permittivity of free space; $\varepsilon r^{\prime}$ represents the relative dielectric constant; and हeff " is the effective relative dielectric loss factor. For convenience, the loss mechanisms are all combined together in one loss parameter, $\varepsilon_{e f f}$ ". However, the loss tangent, $\tan \delta$, is commonly used to describe these losses, as follows:

$$
\tan \delta=\varepsilon_{e f f}{ }^{\prime \prime} / \varepsilon_{r^{\prime}}=\sigma /\left(2 \pi f \varepsilon_{0} \varepsilon_{r}\right)
$$

where $\sigma$ represents the total effective conductivity $(\mathrm{S} / \mathrm{m})$ caused by conduction and displacement currents and $\mathrm{f}$ denotes the frequency $(\mathrm{Hz})$.

The power absorbed per unit volume, $P(\mathrm{~W} / \mathrm{m})$, provides the following basis for heating:

$$
P=\sigma / E / 2=\left(2 \pi f \varepsilon_{0} \varepsilon_{r}\right) / E / 2 \tan \delta
$$

where $E(V / m)$ represents the magnitude of the internal field. Equation (11) shows that the power absorbed, $P$, varies linearly with the frequency, $f$, the relative dielectric constant, $\varepsilon 0$, the loss tangent, $\tan \delta$, and the square of the electric field, $\mathrm{E}$.

The relative dielectric constant $\left(\varepsilon r^{\prime}\right)$ and the loss tangent $(\tan \delta)$ are the two most widely used and measured parameters that describe the behavior of a dielectric under the influence of a microwave field. The value of $\varepsilon r^{\prime}$ is a measure of the polarizability of a material in an electric field, whereas the value of $\tan \delta$ is a measure of the loss (or absorption) of the microwave energy 
within the material. They both affect the power absorbed and the half-power depth. Thus, they influence the volumetric heating behavior of a given material.

During heating, $\varepsilon_{r}$ and tan $\delta$ change with temperature. A knowiedge of these changes is important for process control. The increase in $\varepsilon_{r}{ }^{\prime}$ with temperature is due to an increase in the polarizability caused by volumetric expansion. In contrast to $\varepsilon_{r}{ }^{\prime}, \tan \delta$ is far more affected by temperature. The rapid increase in $\tan \delta$ in polycrystalline ceramics is associated with the softening of the intergranular and amorphous phases, which causes an increase in the local conductivity, $\sigma$.

\subsection{SAFETY AND REGULATORY CONCERNS}

The experiments conducted in FY96 adhered to all regulatory requirements.

Lambda Technologies, the sole manufacturer of the variable frequency microwave furnace, has gone to great lengths to ensure that any microwave energy that leaks out of the cavity or the microwave chain is orders of magnitude lower than the Occupational Safety and Health Administration (OSHA)-established microwave exposure thresholds. 


\section{EXPERIMENTAL INVESTIGATION}

Bauxite is widely used in producing refractory for the containment of high-temperature industrial processes. Refractory-grade bauxite is prepared from high purity bauxite by calcining at a temperature of around $1650^{\circ} \mathrm{C}$. Bauxite consists of three minerals-gibbsite, dispore, and boehmite-which occur in various proportions in different deposits. The calcining process removes both moisture and chemically bound water and converts the bohemite, dispore, and gibbsite forms of alumina to corundum. Clay minerals (e.g., kaolnite) and sometimes a small proportion of the free silica are converted to mullite.

The country of Guyana has large amounts of high-grade bauxite deposits (Munroe 1977). Four types of bauxite corresponding to different stages of Guyana Linmine, Inc.'s beneficiation processes were chosen as starting materials for this investigation. The exposed bauxite is mined by drilling and blasting and is then fed to hammer mills via crushers, providing minus 4 mesh feed (type A, raw bauxite). The feed is then washed in several stages to remove the minus 10 mesh fraction (type $B$, traditional bauxite). The washing process reduces the silica content of the kiln feed by approximately 2 percent. The minus 10 mesh fraction is disposed of in the tailings impoundment (type $\mathrm{C}$, tailing pond material). The bauxite ore horizon in the Linden mine area is overlain by a high-silica bauxite capping, which is the type D bauxite capping material.

Work completed in FY96 consisted of the sintering of these four types of bauxite extrudates to produce a range of refractory materials. The air-dried pellets were fired in an electrical furnace under a 1 psi helium atmosphere at $5^{\circ} \mathrm{C} / \mathrm{min}$ to a given temperature $\left(1450^{\circ}, 1550^{\circ}, 1650^{\circ}\right.$, and $1750^{\circ} \mathrm{C}$ ), at which it was held for either one or four hours. The pellets were then cooled inside the furnace.

\subsection{EXPERIMENTAL PROCEDURES}

The sintered extrudates were subjected to four experimental measurements: volume contraction, weight loss, apparent porosity, and specific gravity. The microstructure of the sintered pellets was examined with a scanning electron microscope (SEM) and energy dispersive analysis by $\mathrm{X}$ rays (EDAX). The mineralogical composition of the extrudates after sintering has also been determined using X-ray diffractometry (XRD).

\subsubsection{Volume Contraction}

The dimension of each sample (radius and length) was measured prior to and proceeding the firing. Samples were assumed to be perfect cylinders and were measured several times to reduce the error risk in the calculating volume.

The volume was calculated by

$$
V=1 / 4 \pi r^{2} h
$$

where $r$ represents the radius of the sample and $h$ denotes the height of the sample.

The results were converted to percent volume contraction $\left(\% \mathrm{~V}_{\mathrm{C}}\right)$ as follows: 


$$
\% \mathrm{~V}_{\mathrm{C}}=\left(\mathrm{V}_{\text {loss }} / \mathrm{V}_{\text {initial }}\right) * 100 \%
$$

\subsubsection{Weight Loss}

The weight of each sample was taken before and after firing. The weight loss was determined as follows:

$$
\text { Weight Loss }=\mathrm{W}_{\text {initial }}-\mathrm{W}_{\text {final }}
$$

\subsubsection{Apparent Porosity}

The apparent porosity was estimated from the amount of water or other suitable fluid absorbed by a given weight or volume of the sample. Hence, absorption is a measure of the volume of unsealed pores. The following procedure was employed to determine apparent porosity:

1. The dried sample was weighed $\left(\mathrm{W}_{1}\right)$;

2. The sample was placed in a vacuum vessel and evacuated to ensure that the liquid completely filled all unsealed pores;

3. Without releasing the pressure (i.e., maintaining the vacuum), the immersion liquid was introduced to such a level that the piece was entirely covered;

4. The saturated sample was then weighed in air $\left(\mathrm{W}_{2}\right)$ by suspending it from a thread attached to the arm of the balance; and

5. The weight of the sample when immersed in water was measured $\left(\mathrm{W}_{3}\right)$.

The weight of the liquid absorbed was given by $W_{2}-W_{1}(g)$. Assuming that water (density $=1$ ) was used for immersion, this quantity also represents the volume of the open pore space in $\mathrm{cm}^{3}$. The total volume of the test piece, $\mathrm{W}_{2}-\mathrm{W}_{3}$, was the weight lost on immersion in water. Therefore, the percentage apparent porosity by volume $(\mathrm{P})$ was expressed by the equation:

$$
\mathrm{P}=\left[\left(\mathrm{W}_{2}-\mathrm{W}_{1}\right) /\left(\mathrm{W}_{2}-\mathrm{W}_{3}\right)_{\star} \mathrm{p}\right]
$$

where $\rho$ is the density of the liquid ( 1 if water were used).

\subsubsection{True Specific Gravity}

True specific gravity was determined as follows:

1. The material was ground to a fine powder so that the individual grains were too small to contain pores;

2. The true specific gravity of the powder was determined by means of a specific gravity bottle (a pycnometer or a Rees-Hugill flask);

3. The bottle and stopper were cleaned, dried, and weighed (P);

4. A sufficient quantity of the dry powder (crushed to pass a $120 \mathrm{BSI}^{*}$ sieve) was placed in the pycnometer to half fill the bottle, which was then weighed $\left(\mathrm{W}_{1}\right)$;

• British Standards Institute 
5. The weight of the powder was then given by $\left(\mathrm{W}_{1}-\mathrm{P}\right)$;

6. The bottle was filled with water, and all air was evacuated. To obtain satisfactory results, the bottle was filled under a vacuum, and distilled water was used. The water was boiled to eliminate dissolved air and then cooled in the absence of air;

7. As the specific gravity of water varies with temperature, the filled, stoppered bottle was placed in a thermostat until its temperature was constant. Excess water that overflowed through the stopper was removed with some tissue paper. The bottle and its contents were weighed $\left(\mathrm{W}_{2}\right)$;

8. The bottle was then emptied, cleaned, refilled with distilled water, and again brought to constant temperature prior to weighing again $\left(\mathrm{W}_{3}\right)$; and

9. The volume of the bottle was $\left(\mathrm{W}_{3}-\mathrm{P}\right) / \rho$, where $\rho$ is the density of the water or any fluid used at the test temperature.

The true specific gravity was calculated from the following expression:

$$
\text { S.G. }=\left(W_{1}-P\right) \rho /\left[\left(W_{3}-P\right)-\left(W_{2}-W_{1}\right) \rho\right]
$$

\subsection{MICROSTRUCTURE OBSERVATION AND ANALYSIS (SEM AND EDAX)}

Pellets sintered under a helium atmosphere for one hour at $1450^{\circ}$ and $1550^{\circ} \mathrm{C}$ were crosssectioned. After careful grinding and mechanical polishing, the samples were gold coated and then examined using scanning electron microscopy (SEM). The elemental contents of microareas were semiquantitatively analyzed using the method of energy dispersive analysis by X-rays $(\mathrm{EDAX})$.

\subsection{POWDER X-RAY DIFFRACTION (XRD)}

Commercial micron powders of mullite, corundum, and cristobalite were used as the reference materials. Fluorite was applied as the internal standard material. The reference powders and the internal standard powders, respectively, were placed in an agate motor according to a predetermined weight ratio. Two weight ratios of fluorite, 50 percent and 10 percent, were used to ensure the accuracy of the obtained $\mathrm{K}$ value (the slope of the calibration curve). The powders were covered with 10 milliliters of ethyl ether as the mixing solvent. The slug was stirred with a pestle until the liquid completely evaporated. Stirring considerably increases the degree of mixing.

The extrudates sintered under a helium atmosphere for four hours at $1450^{\circ}, 1550^{\circ}, 1650^{\circ}$, and $1750^{\circ} \mathrm{C}$ were crushed for 20 minutes to pass the 200 -mesh sieve. These powders were mixed with 10 percent fluorite in the same manner noted above. The mixtures were then exposed to Xrays, and the diffraction peak intensity was recorded. The contents of mullite, corundum, and cristobalite were determined according to the peak intensity ratio and the $\mathrm{K}$ value. 


\section{EXPERIMENTAL RESULTS}

The chemical composition of the starting materials was analyzed by EDAX, and the mineral phases were identified by XRD. The apparent porosity, specific gravity, volume contraction and weight loss of the extrudates fired under helium for four hours were determined. The content of mullite, corundum and cristobalite was quantitatively determined using an internal standard method (Fan 1980). In addition, the microstructure of extrudates fired under helium for one hour was examined by SEM.

\subsection{CHARACTERIZATION OF THE STARTING MATERIALS}

Semiquantitative elemental analysis by EDAX indicates that titapium and iron were the main impurities in the starting materials. Minor amounts of yanadium were detected only in the capping material. The elemental composition of the starting mateials as evaluated by EDAX are presented in Table 1 as well as the maximum mullite $\left(3 \mathrm{AI}_{2} \mathrm{O}_{3} \cdot 2 \mathrm{SiO}\right)$ yield as calculated from the chemical composition.

Table 1.

Composition of the Starting Bauxite Materials

\begin{tabular}{|c|c|c|c|c|c|c|c|c|c|c|c|c|c|c|}
\hline SAMPLE & $\underset{*}{\mathrm{SLO}_{2}}$ & $\underset{\%}{\mathrm{AL}_{2} \mathrm{O}_{2}}$ & $\begin{array}{c}\text { CAO } \\
*\end{array}$ & $\begin{array}{c}\text { MGO } \\
\mathbf{x}\end{array}$ & $\begin{array}{c}\mathrm{NA}_{2} \mathrm{O} \\
*\end{array}$ & $\begin{array}{c}\mathrm{K}_{2} \mathrm{O} \\
\times\end{array}$ & $\begin{array}{c}\mathrm{Fe}_{2} \mathrm{O}_{2} \\
\times\end{array}$ & $\begin{array}{c}\text { MNO } \\
\times\end{array}$ & $\begin{array}{c}\mathrm{Cr}_{2} \mathrm{O}_{3} \\
*\end{array}$ & $\underset{\mathbf{m o}}{\mathrm{no}}$ & $\begin{array}{c}P_{2} O_{8} \\
\times\end{array}$ & $\begin{array}{c}\text { LOI } \\
*\end{array}$ & $\underset{\text { PPM }}{V}$ & $\begin{array}{c}\text { SUM } \\
\%\end{array}$ \\
\hline $\begin{array}{l}\text { RAW BAUXITE } \\
\text { TRAD. BAUXITE }\end{array}$ & $\begin{array}{l}5.51 \\
5.51\end{array}$ & $\begin{array}{l}60.2 \\
60.4\end{array}$ & $\begin{array}{l}<0.01 \\
<0.01\end{array}$ & $\begin{array}{l}<0.01 \\
<0.01\end{array}$ & $\begin{array}{l}<0.01 \\
<0.03\end{array}$ & $\begin{array}{l}<0.01 \\
<0.01\end{array}$ & $\begin{array}{l}0.81 \\
1.1\end{array}$ & $\begin{array}{l}<0.01 \\
<0.01\end{array}$ & $\begin{array}{l}0.06 \\
0.08\end{array}$ & $\begin{array}{l}2.95 \\
2.52\end{array}$ & $\begin{array}{l}0.04 \\
0.05\end{array}$ & $\begin{array}{l}30.8 \\
30.9\end{array}$ & $\begin{array}{l}200 \\
160\end{array}$ & $\begin{array}{l}100.4 \\
100.6\end{array}$ \\
\hline $\begin{array}{l}\text { CAPPING } \\
\text { MATERIAL } \\
\text { TAILING POND }\end{array}$ & $\begin{array}{l}18.4 \\
7.67\end{array}$ & 53.3 & $<0.01$ & $\begin{array}{l}<0.01 \\
<0.01\end{array}$ & $<0.05$ & $<0.01$ & 1.29 & $\begin{array}{l}<0.01 \\
<0.01\end{array}$ & 0.12 & 2.73 & 0.07 & 24.6 & $\begin{array}{l}520 \\
250\end{array}$ & $\begin{array}{l}100.5 \\
100.7\end{array}$ \\
\hline
\end{tabular}

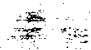

Chemical analyses of the starting materials indicate that the alumina content in the traditional bauxite was higher and the silica content was lower than that contained in the other three materials. Supposing that the stotchiometric amount of alumina and silica in each type of extrudate combined to produce - maximum amount of mullite during the firing, then the fired products of raw bauxite, traditional bauxite, and tailing pond material should be composed of mullite and corundum in the case of capping material, the fired product is expected to be composed of mullite and cristobalite. The traditional bauxite is expected to yield the lowest content of mullite due to the low content of silica. The capping material is expected to yield the highest mullite content hate to it high silica content.

The mineralogical composition of the starting material, identified by powder X-ray diffraction analysis, is shown in Figure 3. Gibbsite was the dominant mineral in each of the starting materials. Minor amounts of kaolinite were also detected in each. However, less gibbsite and much more kaolinite were detected in the capping material as compared to the other bauxite materials. 


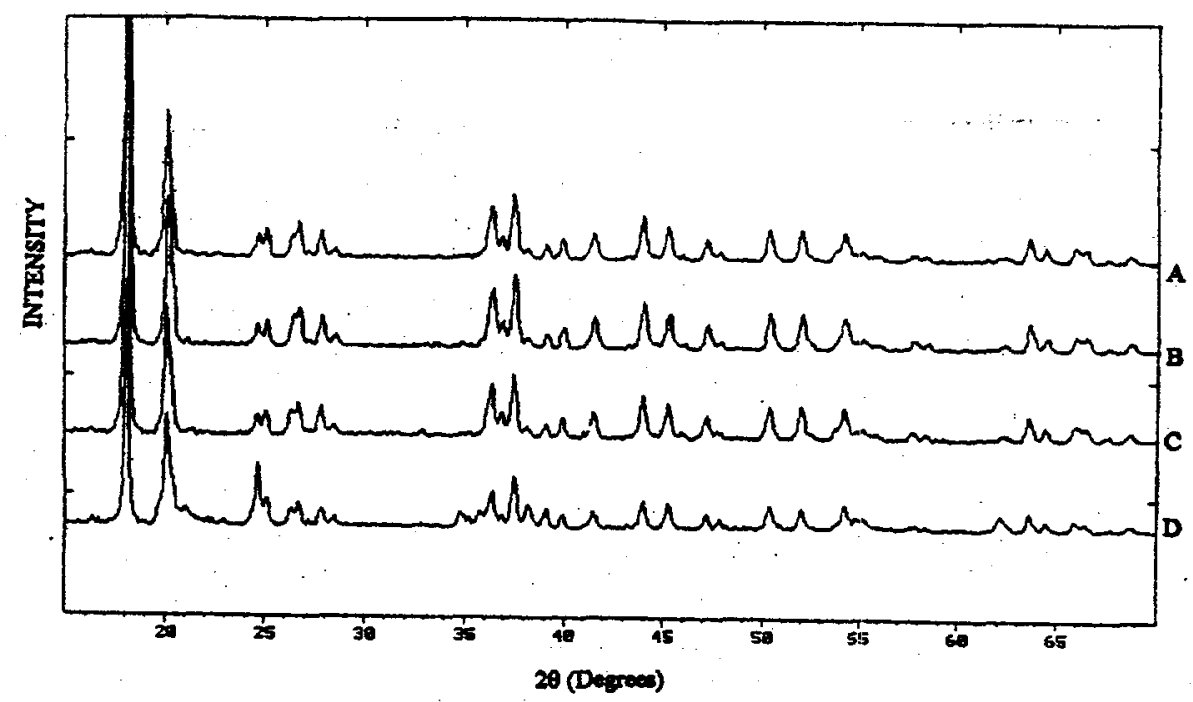

Figure 3. Mineralogical composition of the starting material.

The starting materials contained gibbsite and kaolinite, which decomposed when the pellets were heated. Gibbsite decomposes at about $325^{\circ} \mathrm{C}$ and yields $\gamma$-alumina with 34.6 percent water loss. Calcination at a temperature above $160 \% \mathrm{C}$ results in the conversion of all forms of alumina to corundum. Kaolinite is first dehydrated at $500^{\circ}$ to $600^{\circ} \mathrm{C}$ during heating, with 14.1 percent water loss (Grimshaw 1971). The dehydrated kadinite (metakaolinite) is not compatible with aluminasilica according to the $\mathrm{SiO}_{2}-\mathrm{Al}_{2} \mathrm{O}_{3}$ phase diagram. However, it is well know the impurity containing metakaolinite undergoes a series of reactions above $980^{\circ} \mathrm{C}$, resulting in mullite crystals, silica, and an impurity containing silica-rich liquid. The latter two then react with alumina to form mullite upon further heating (Liu et al. 1994).

\subsection{PHYSICAL PROPERTIES}

Figures 4 through 7 illustrate the apparent porosity, true specific gravity, volume contraction, and weight loss, respectively, of the four types of aluminosilicate extrudates as a function of sintering temperature. The soaking time was four hours.

Figure 4 depicts the apparent porosity of the fired extrudates. It can be observed that the apparent porosity increases with increasing firing temperature. 


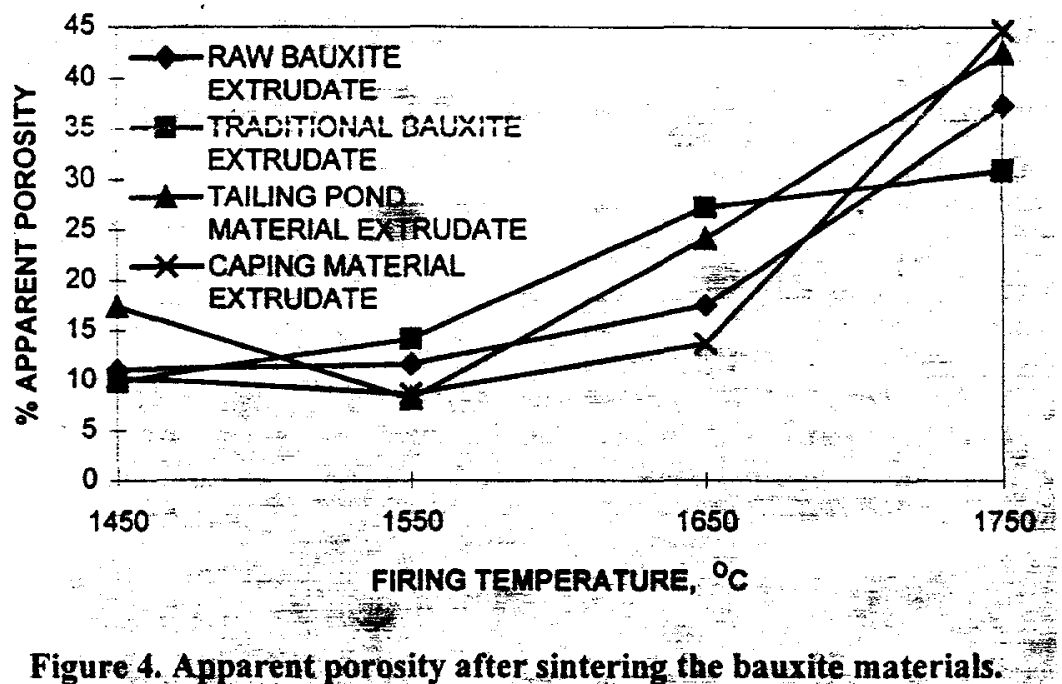

Figure 4. Apparent porosity after sintering the bauxite materials.

Figure 5 shows the relationship between specific gravity and firing temperature. The specific gravity of the fired pellets of traditional bauxite and tailing pond material increases with the firing temperature. The specific gravity in the raw bauxite and capping material shows some irregular changes with firing temperature. The change of the specific gravity indicates that the mineral composition varies with the firing temperature.

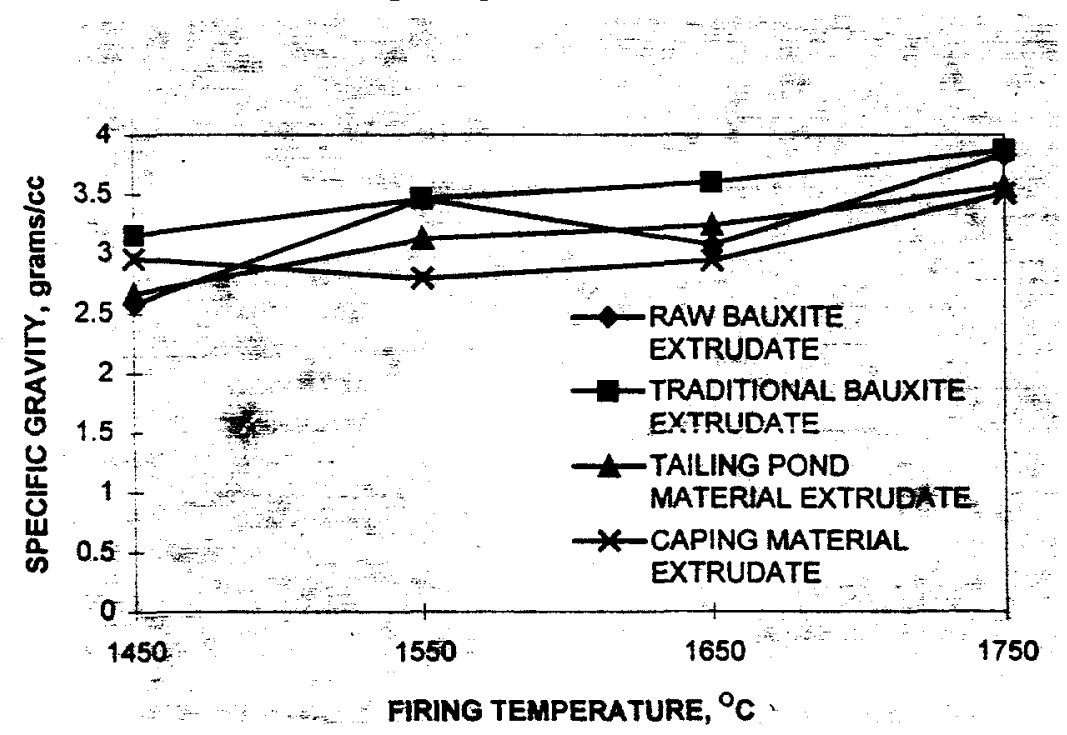

Figure 5. Specific gravity after sintering the bauxite materials.

The volume contraction after firing the extrudates is shown in Figure 6 . The pellets cracked significantly in the interior when the temperature exceeded $1550^{\circ} \mathrm{C}$ and the volume associated with interior cracks were not accounted for in the calculation of volume contraction, which utilizes measurements of the outer dimensions of the fired extrudates. 


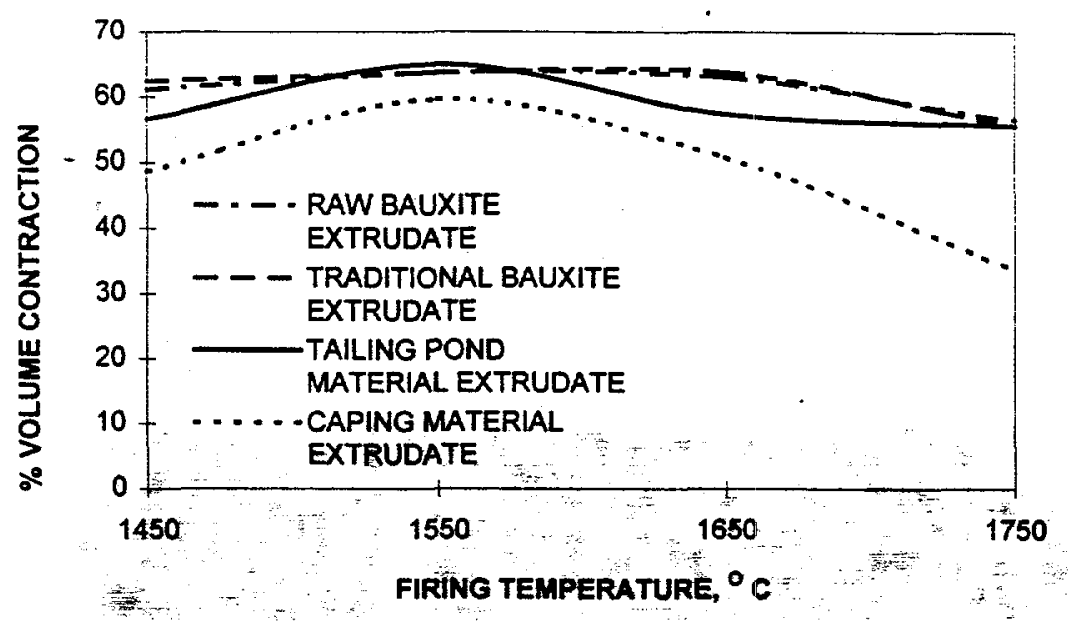

Figure 6. Volumegontraction after sintering the bauxite materials.

Figure 7 shows the weight 10 ss of the pellets during firing. The weight loss during firing is attributed to the evaporation of moisture and the absorbed water, the ignition of organic materials, and the liberation of chemicalfy bound water. Gibbsite decomposes at about $325^{\circ} \mathrm{C}$ with 34.6 percent water loss. Kaolinite dehydrates at $500^{\circ}$ to $600^{\circ} \mathrm{C}$ during heating.

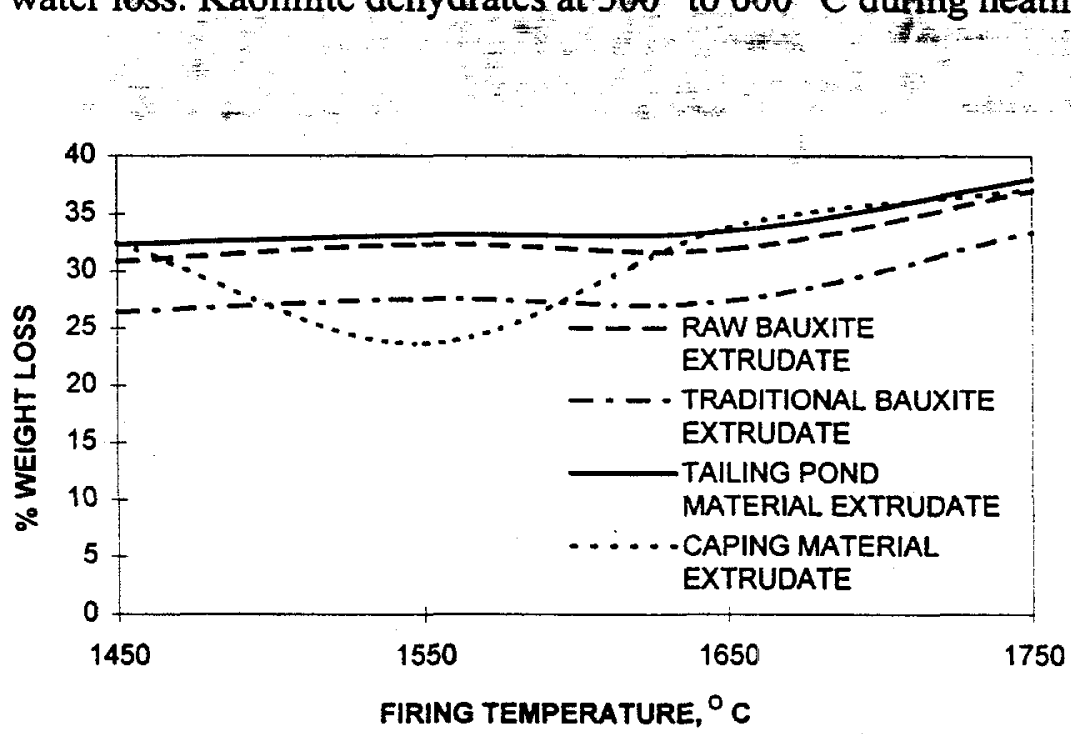

Figure 7. Weight loss after sintering the bauxite matèrials.

\subsection{DETERMINATION OF THE K VALUE}

The powder sample is assumed to be a uniform mixture of $n$ components with a particle size small enough to ensure that a large amount of particles is exposed to the X-ray beam. With such a powder sample, the total intensity of X-ray diffraction by the $J_{\mathrm{th}}$ component of the mixture by a selected plane $(h k l)=i$ is given by: 


$$
I_{i} J=K_{i J} \bar{x} \mathcal{J} \neq \rho J \mu^{*}
$$

where $K_{i . J}$ represents the coefficient and $\rho_{J}$ and $x_{J}$ denote the density and weight fraction of the component, respectively, whereas $\mu^{*}$ represents the mass absorption coefficient of the unknown mixture.

If an internal standard, component $\mathrm{S}$, is added to the sample in a known amount and that the weight fraction of the unknown and internal standard components after such addition are $x J$ and $x_{S}$ and are related to $x_{J}$ as follow

then

$$
x J=x J^{\prime} /\left(1-x_{S}^{\prime}\right)
$$

Dividing $I_{i J}$ by $I_{k S}$ yields the following expression:

$$
I_{i J} / I_{k S}=\left(K_{i J} \rho_{S} / K_{k S} \rho_{J}\right) x J^{\prime} / x_{S}{ }^{\prime}=K_{S} x_{J^{\prime}} / x_{S^{\prime}}
$$

where $K^{J} S$ denotes a constant, which is independent from the weight fraction of the unknown and internal standard components, the existence of other components, and the geometric condition of X-ray diffraction (Fan 1980).

According to Equation (20), when preparing a two-component (the $J_{\mathrm{th}}$ component and the internal standard component) value mixture at a weight ratio of $1: 1$, the intensity ratio $I_{i J} / I_{k S}$ is equal to $K^{J} S$.

By combining Equations (18) and (20), the weight fraction of the $J_{\text {th }}$ component in the original mixture can be determined when the intensity ratio is measured.

This modified internal standard does not require the preparation of a series of different content of the $J$ component mixture at a constant proportion of the internal standard material to obtain the calibration curve. Actually, $K^{J} S$ is the slope of the calibration curve.

\subsubsection{K Value of the Reference Materials}

Three types of two-component reference mixtures-corundum and fluorite, mullite and fluorite, cristobalite and fluorite-were prepared. The intensities of the $2.38 \AA$ corundum peak, the $2.21 \AA$ mullite peak, the $4.05 \AA$ cristobalite peak, and the $3.16 \AA$ fluorite peak were calculated by multiplication of the height of the peak and the width of the peak at half-height. According to Equation (20), the intensity ratio is used to determine the $K^{A} F, K^{M}{ }_{F}$, and $K_{F} C_{F}$, respectively. In order to minimize error, the reference mixtures with different weight fractions of fluorite were prepared for the $K^{A} F$ and $K^{M} F$. Table 2 lists the $K$ value and indicates that this value is accurate. 
Table 2.

$K$ Value Determined from the Synthetic Mixtures

\begin{tabular}{|c|c|c|c|}
\hline Fluorite Content (wt. \%) & Corundum/Fluorite & Mullite/Fiuorite & Cristobaiite/Fluorite \\
\hline 50.00 & 0.1060 & 0.1135 & 1.0841 \\
\hline 10.00 & 0.1064 & 0.1112 & Not determined \\
\hline
\end{tabular}

\subsection{PHASE FRACTION IN THE MIXTURE OF THE SINTERED PELLETS}

Figure 8 (a)-(d) depicts the X-ray diffraction patterns of powdered mixtures of 90 percent fired extrudate and 10 percent calcium fluoride. All the fired pellets consisted of three crystalline phases: corundum, mullite, and cristobalite. The height of the peaks qualitatively indicates the mineral contents at different firing temperatures. As shown in Figure 8(a), corundum peaks of Xray diffraction patterns (denoted as " $\mathrm{A}$ ") for fired raw bauxite were higher at $1450^{\circ}$ and $1650^{\circ} \mathrm{C}$ than those obtained at $1550^{\circ}$ and $1750^{\circ} \mathrm{C}$, respectively. The height of mullite peaks (denoted as "M") steadily decreased with increasing temperature. In the fired traditional bauxite, as shown in Figure $8(\mathrm{~b})$, the height of corundum peaks steadily increased, whereas that of the mullite peaks decreased with increasing temperature. The X-ray diffraction pattern as a function of temperature for the fired tailing pond material was similar to that of fired traditional bauxite, as can be observed in Figure 8(c). As shown in Figure 8(d), the corundum peaks of the fired capping material were quite short, whereas the mullite peaks were tall but decreased with increasing temperature. 
(a)

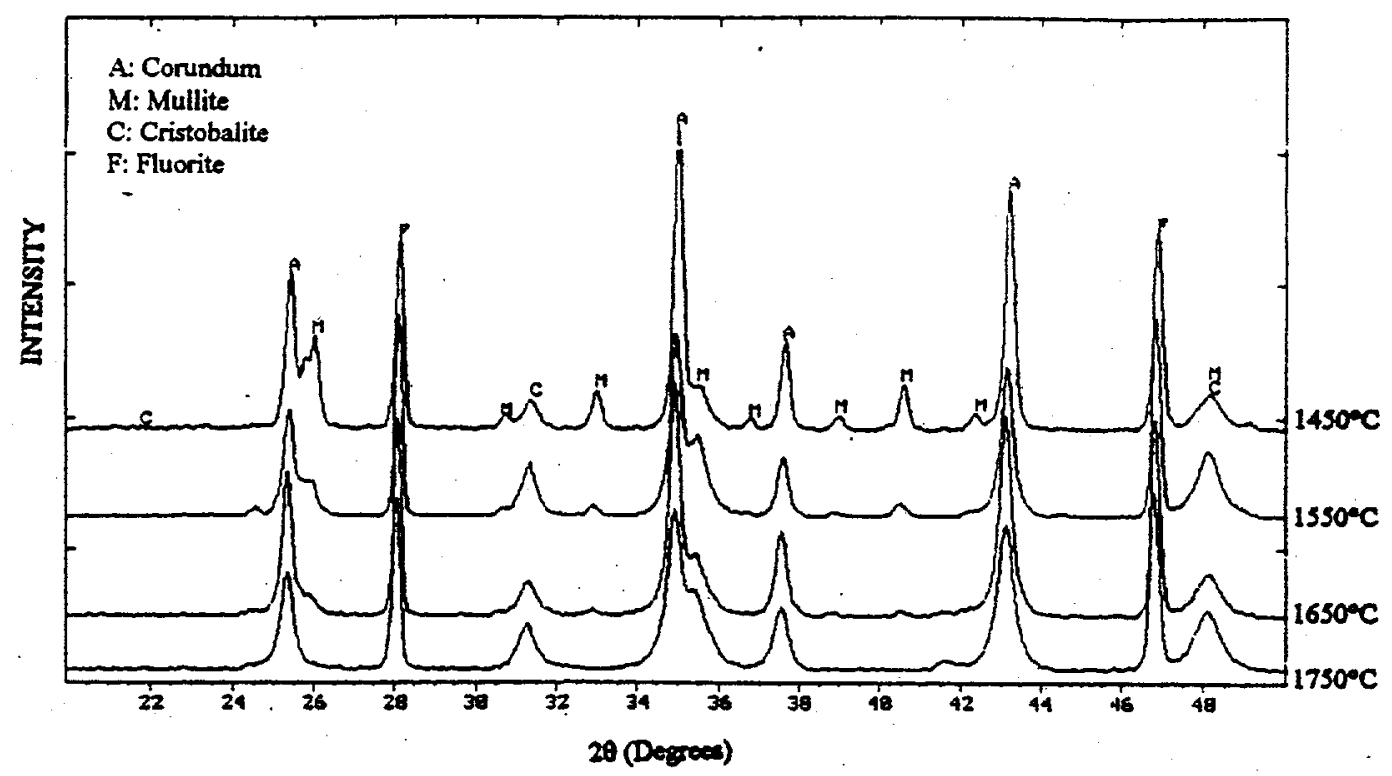

(b)

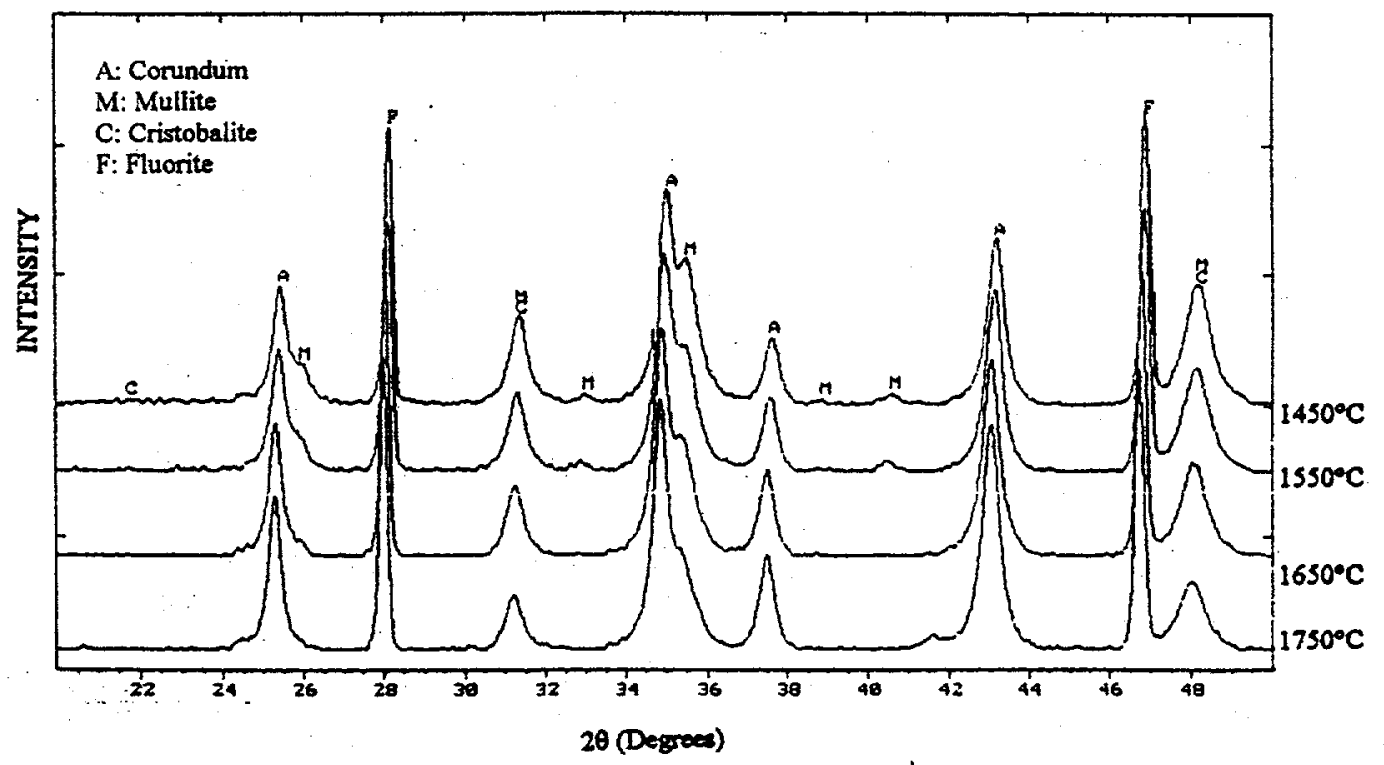

Figure 8. Powder X-ray diffraction pattern of (a) raw bauxite, (b) traditional bauxite. 
(c)

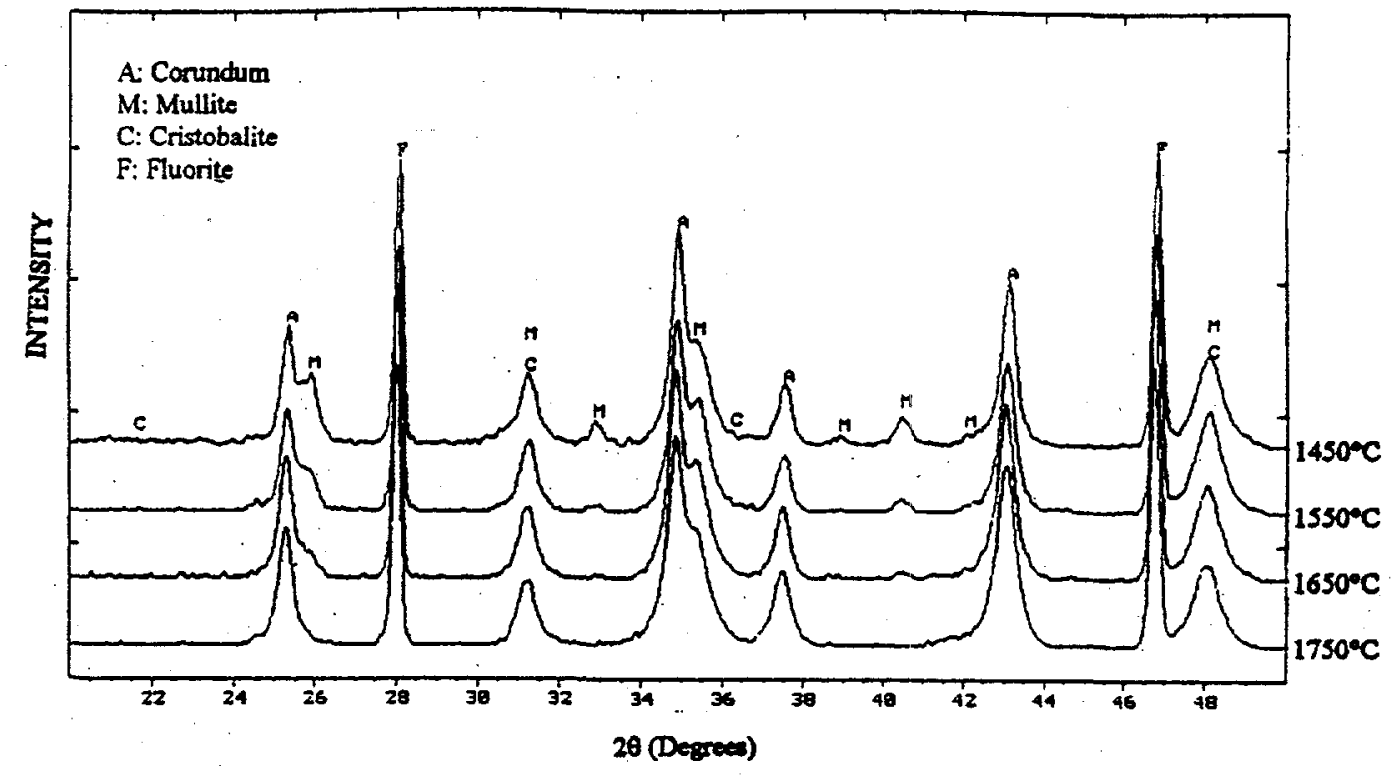

(d)

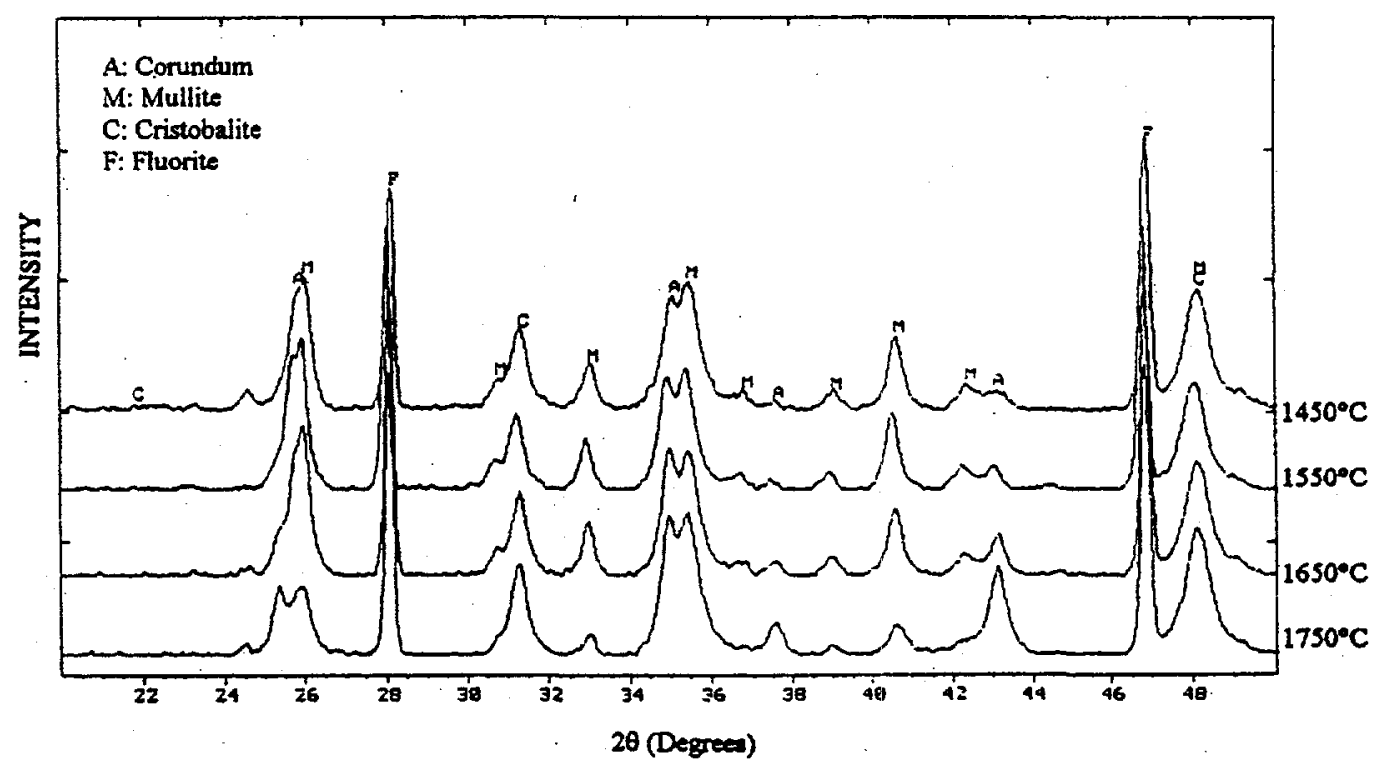

Figure 8. Powder X-ray diffraction pattern of (c) tailing pond material, (d) capping material fired at $1450^{\circ}, 1550^{\circ}, 1650^{\circ}$ and $1750^{\circ} \mathrm{C}$.

Figures 9 and 10 show the quantitative results of the XRD analysis. It is clear that the capping material is quite different in composition than raw bauxite, traditional bauxite, and the tailing pond material. It contains much more mullite and much less corundum. The corundum content in raw bauxite decreases from $1450^{\circ}$ to $1550^{\circ} \mathrm{C}$, then increases to a maximum of about 70.1 percent at $1650^{\circ} \mathrm{C}$, and maintains that yield at $1750^{\circ} \mathrm{C}$. The corundum content in the traditional bauxite 
increases with increasing temperature and reaches the same amount as that exhibited by raw bauxite at $1750^{\circ} \mathrm{C}$. The tailing pond material contains less corundum than raw bauxite and traditional bauxite at all firing temperatures. The mullite content in all four types of fired pellets decreases with increasing temperature. Of the four types of bauxite, the traditional bauxite yields the lowest content of mullite during firing. At $1750^{\circ} \mathrm{C}$, almost no mullite is found in raw bauxite, traditional bauxite, or tailing pond material. The cristobalite content in all the fired pellets is around 0.1 percent, which is very low.

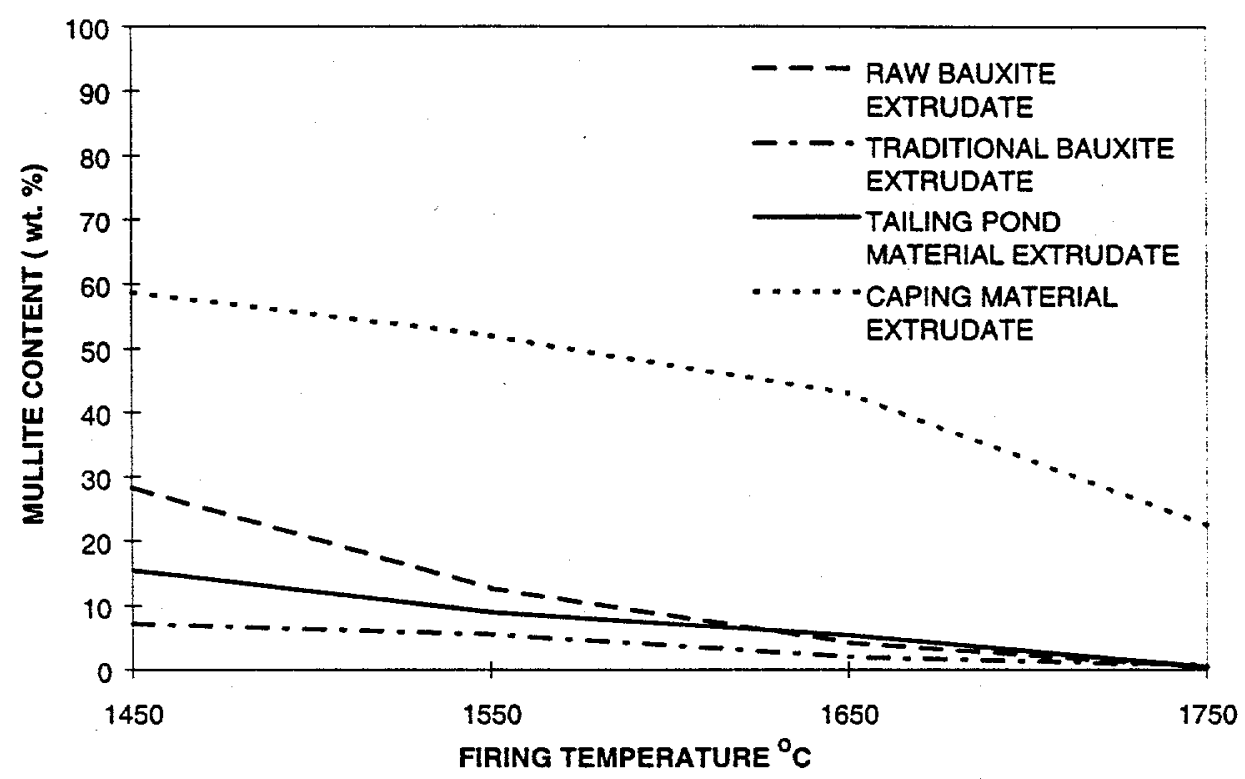

Figure 9. Weight of mullite upon sintering the bauxite materials.

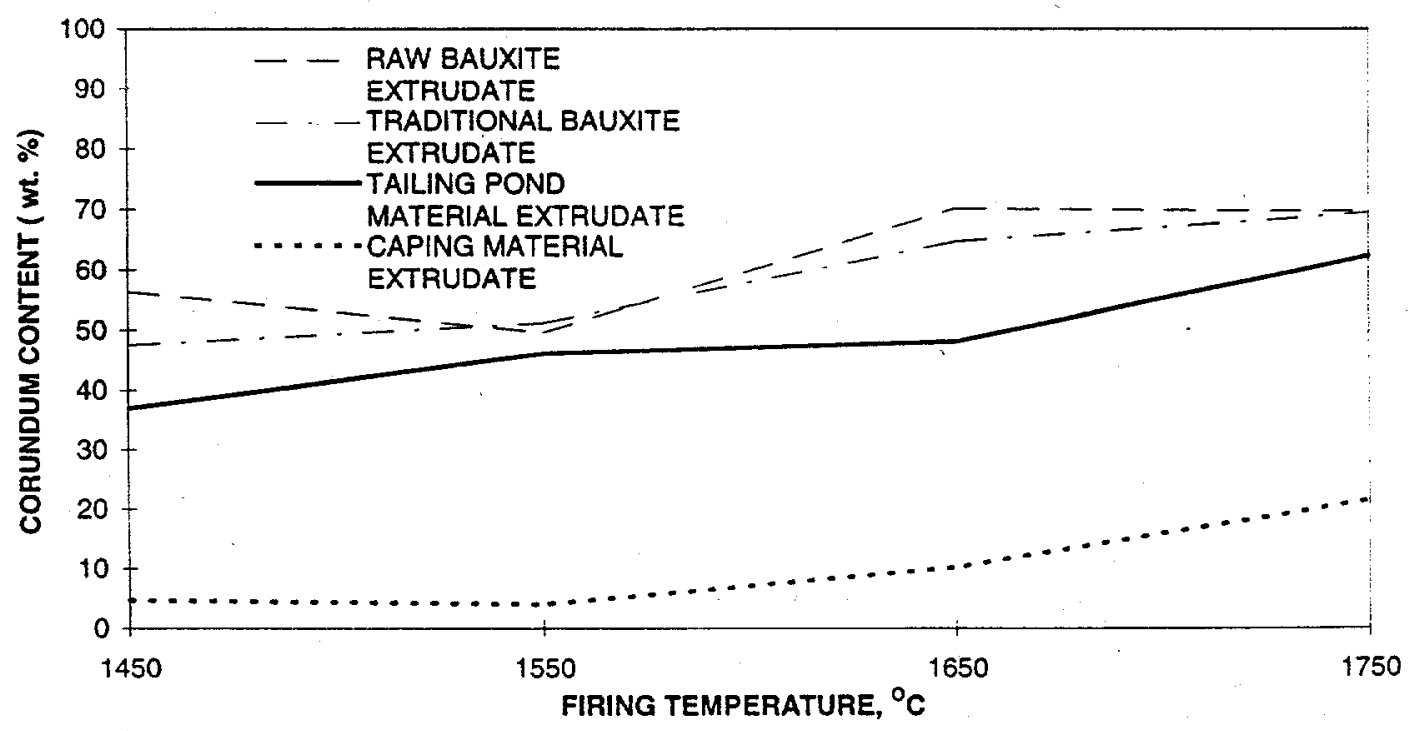

Figure 10. Weight percent of corundum upon sintering the bauxite materials. 
The mullite formation in the pellets is the result of two reactions, the conversion of metakaolinite and the combination of alumina with silica. In the capping material, the former reaction is dominant due to the higher content of kaolinite. This reaction yields a higher content of mullite. It appears that these two reactions are suppressed by the increasing firing temperature. Mullite content decreases with firing temperature in percent condition. This contradicts previous studies (Munroe 1977; Hamano et al. 1994) in which mullite content increases with firing temperature. This opposite trend may be caused by 1) the use of coarse starting material; 2) the use of extruded pellets instead of compacted pellets in the study; 3) the helium atmosphere during firing.

\subsection{SEM EXAMINATION}

Polished cross sections of extrudates fired under a helium atmosphere at $1450^{\circ}$ and $1550^{\circ} \mathrm{C}$ were examined by SEM in order to evaluate the morphology, heterogeneity, and composition of the fired pellets. Photomicrographs of each type of extrudate are shown in Figures 11 through 17.

\subsubsection{Pellets Fired at $1450^{\circ} \mathrm{C}$}

\section{Raw Bauxite}

The matrix of the raw bauxite was composed primarily of mullite and small amounts of $\mathrm{TiO}_{2}$. A high content of $\mathrm{TiO}_{2}$ can sometimes be detected accompanying corundum, which manifests itself as a low-contrast area in the matrix.

\section{Traditional Bauxite}

The traditional bauxite pellet cracked during firing. From the cracked surface of the periphery of the pellet to the interior of the pellet, three distinct morphological layers of microstructures were noted (a surface layer, midlayer, and core). The midlayer, which was approximately 20 to $30 \mu \mathrm{m}$ thick, appeared to have a low porosity, whereas the core consisted of the matrix, pores, and particles embedded in the matrix. $\mathrm{TiO}_{2}$ was detected in all three layers. It is assumed that the midlayer is composed of mullite and cristobalite, while the other two layers contain some corundum in addition to mullite. This is evidenced by the fact that close examination of the core indicates that some crystallites in the pores are pure corundum, as shown in Figure 11. It is interesting to note that the area with low contrast in the lower right of the picture consists of pure iron oxide. 


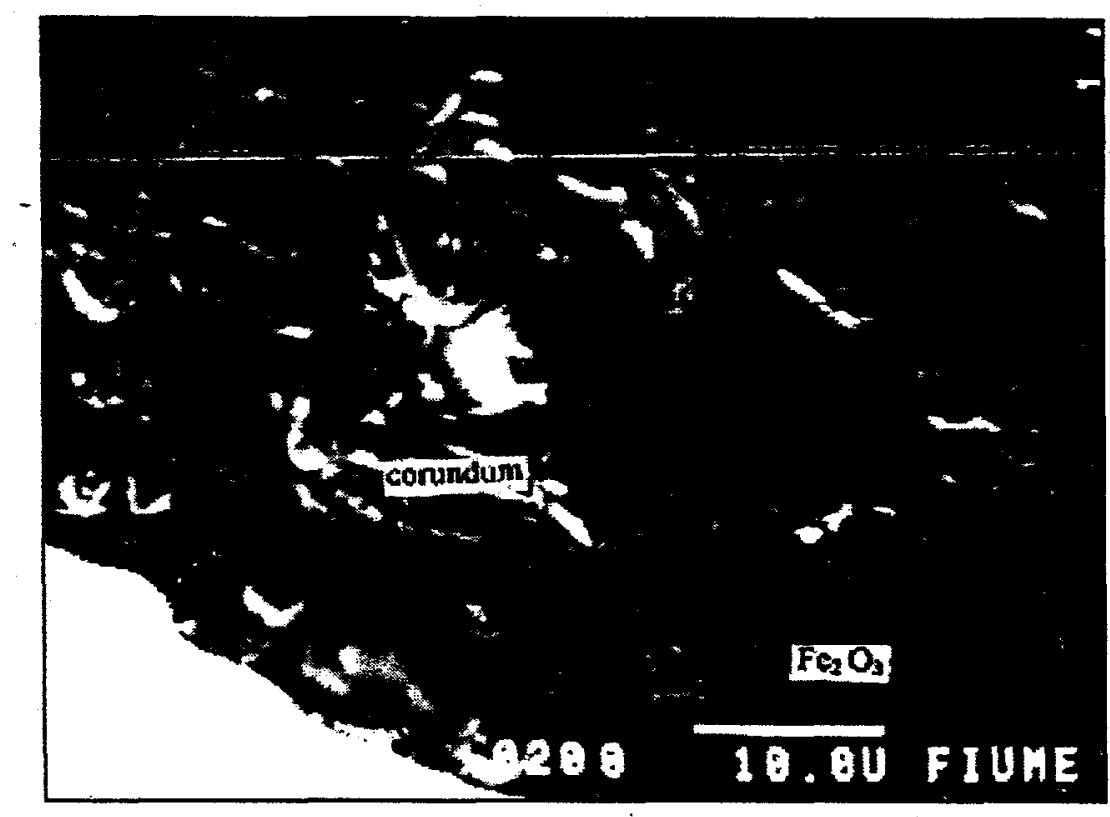

Figure 11. Corundum in a pore and $\mathrm{Fe}_{2} \mathrm{O}_{3}$ segregation (traditional bauxite, $1450^{\circ} \mathrm{C}$ ).

\section{Tailing Pond Material}

The matrix in the tailing pond material was composed of mullite and corundum with small amounts of $\mathrm{TiO}_{2}$. Impurity oxides of the metals $\mathrm{Ti}, \mathrm{Fe}$, and $\mathrm{V}$ segregated in the pores and isolated cristobalite particles appeared in the matrix, as shown in Figure 12.

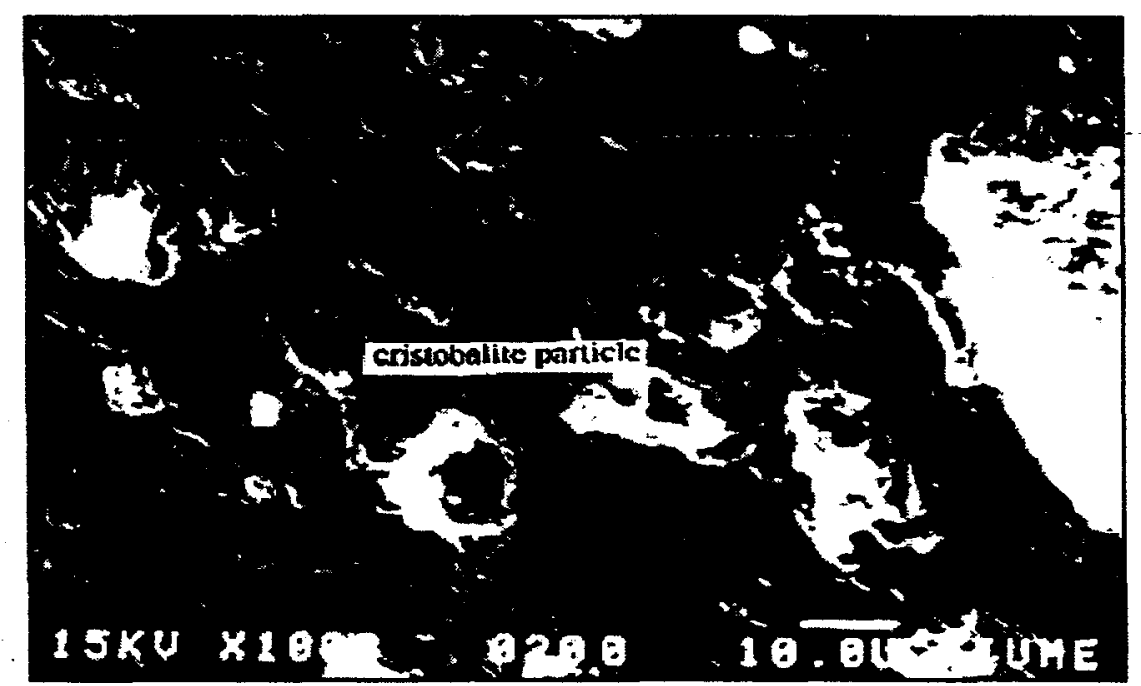

Figure 12. Segregation of impurities in pores and isolated particle of cristobalite (tailing pond material, $1450^{\circ} \mathrm{C}$ ). 


\section{Capping Material}

Particles in the capping material contained the metals $\mathrm{Fe}, \mathrm{Nb}, \mathrm{Ti}$, and $\mathrm{Zr}$ as well as $\mathrm{Al}$ and $\mathrm{Si}$. The matrix consisted of mullite and cristobalite. The surfaces of the pores contained oxides of $\mathrm{Fe}, \mathrm{Zr}, \mathrm{Nb}$, and $\mathrm{Ti}$.

\subsubsection{Pellets Fired at $1550^{\circ} \mathrm{C}$}

Extensive cracks developed in the pellets fired at $1550^{\circ} \mathrm{C}$. The morphology of the microstructure varied from the surface of the pellet or cracked surface to the core of the pellet.

\section{Raw Bauxite}

The surface layer matrix contained mainly corundum and embedded $\mathrm{TiO}_{2}$ particles. Some lowcontrast areas in the matrix were found to be composed of a high content of $\mathrm{TiO}_{2}$ and oxides of $\mathrm{Fe}, \mathrm{Si}$, and $\mathrm{V}$. Particles embedded in the matrix were rich in $\mathrm{Ti}$ and $\mathrm{Fe}$, as shown in Figure 13. The core was composed primarily of mullite.

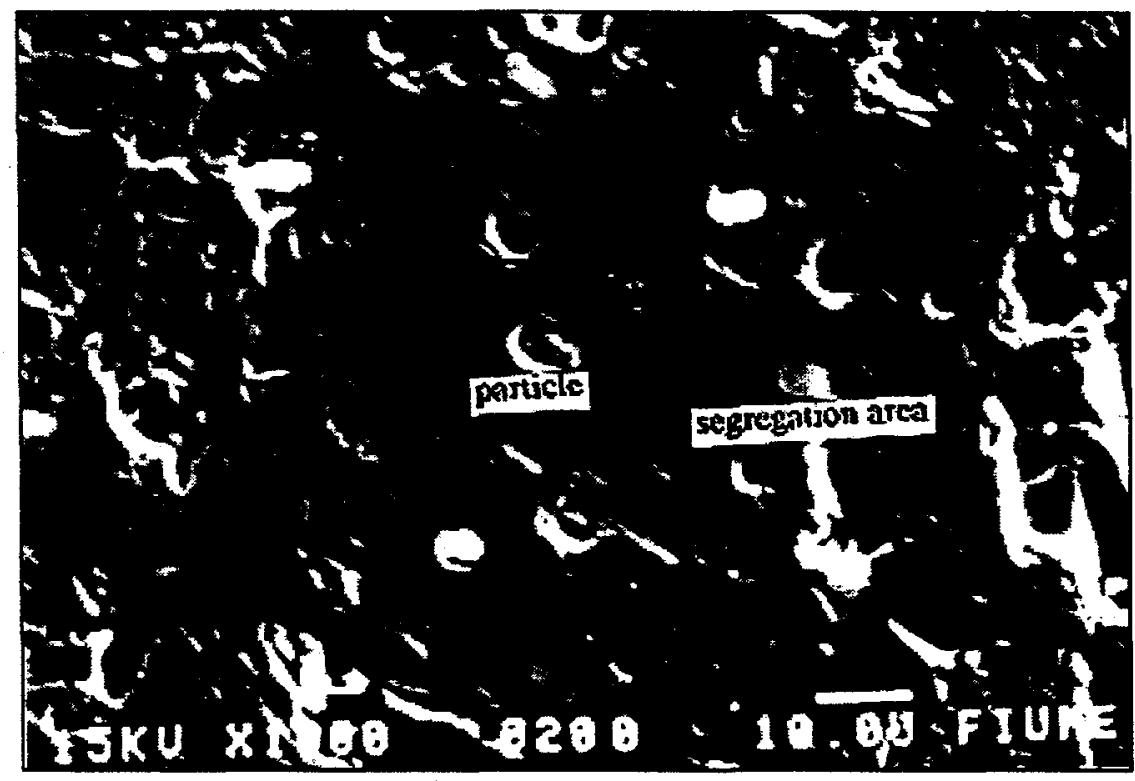

Figure 13. Surface layer of the raw bauxite, $1550^{\circ} \mathrm{C}$.

\section{Traditional Bauxite}

Two distinct layers - a surface layer and the core-were observed in traditional bauxite, as shown in Figure 14. The surface layer, approximately $100 \mu \mathrm{m}$ thick, was comprised of embedded particles rich in corundum. Impurities such as $\mathrm{Ti}, \mathrm{Ca}, \mathrm{K}, \mathrm{Cl}$ and $\mathrm{Na}$ segregated on the surfaces of pores. Corundum particles were also embedded in the pores, as can be observed in Figure 15. The core of the pellet was composed of mullite and a small amount of cristobalite. 


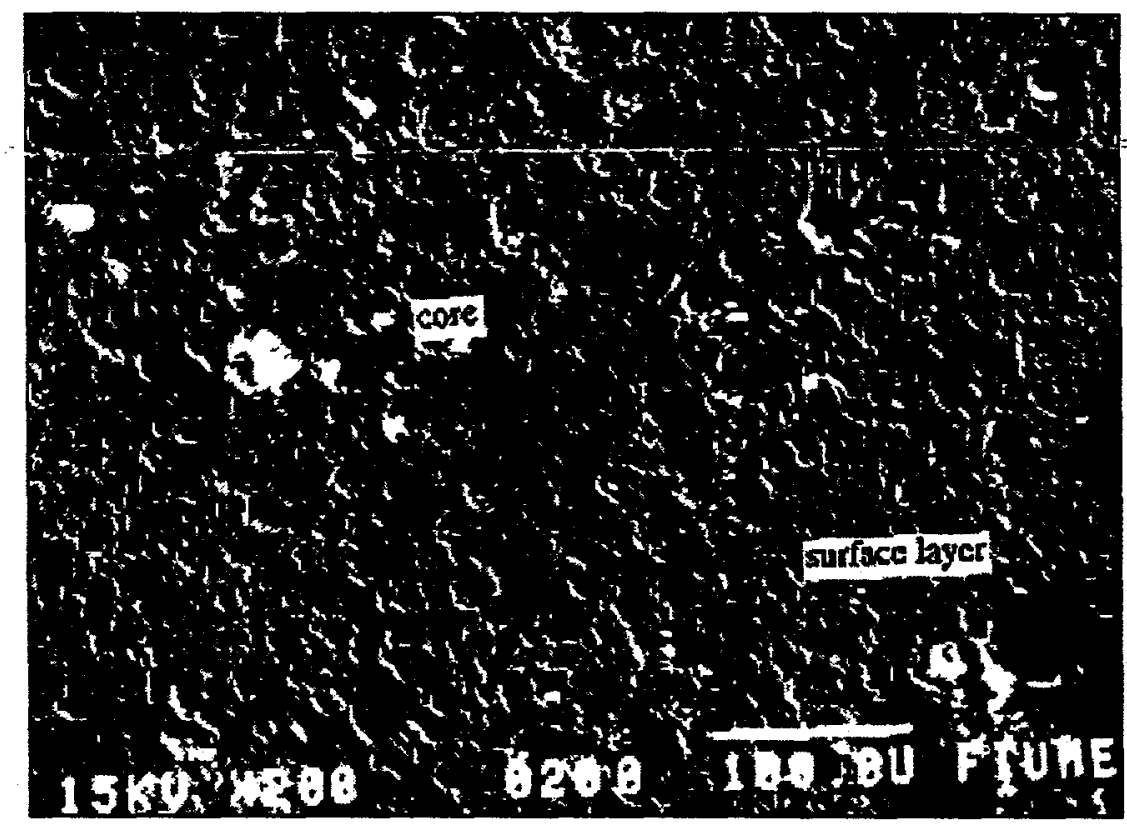

Figure 14. Two layers in the traditional bauxite, $1550^{\circ} \mathrm{C}$.

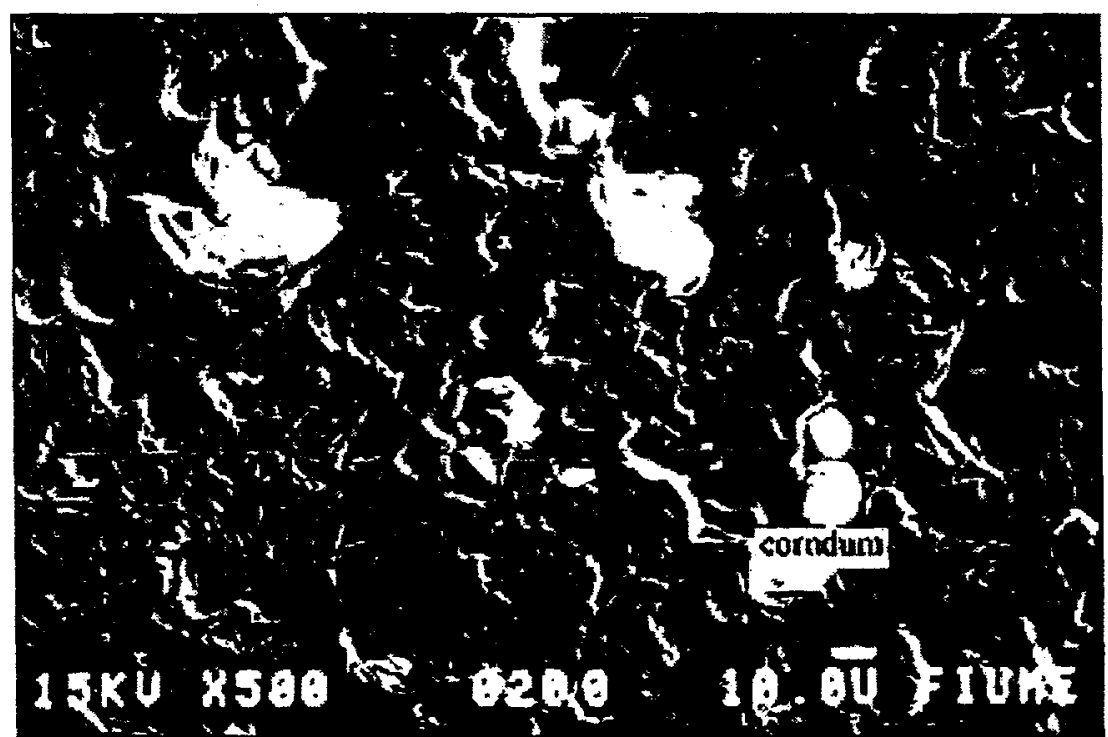

Figure 15. Corundum particle and segregated impurities in the surface layer (traditional bauxite, $1550^{\circ} \mathrm{C}$ ).

\section{Tailing Pond Material}

The surface layer of the tailing pond material sintered at $1550^{\circ} \mathrm{C}$ possessed irregularly shaped pores. The matrix consisted of corundum and mullite with minor amounts of $\mathrm{Ti}$ and $\mathrm{Ca}$. Figure 16 shows the surface of a pore in this layer. The composition in the pore is complex. The whisker 
noted as " 1 " was composed of corundum and $\mathrm{TiO}_{2}$. The whisker noted as " 2 " contained a large fraction of $\mathrm{Cl}$, some corundum, and $\mathrm{Na}_{2} \mathrm{O}$. The presence of $\mathrm{Mg}, \mathrm{Si}, \mathrm{K}, \mathrm{Ca}, \mathrm{Fe}$, and $\mathrm{Ti}$ was also detected. The irregularly shaped particle embedded in the matrix (noted as " 3 ") was analyzed to. be corundum. The composition of the pore surface varied considerably. Some pore surfaces were rich in $\mathrm{TiO}_{2}$; others were rich in $\mathrm{Fe}_{2} \mathrm{O}_{3}$. Elements of $\mathrm{V}, \mathrm{Ca}$, and $\mathrm{Cr}$ were also detected in pores. The matrix of the core consisted of mullite, cristobalite, and minor amounts of $\mathrm{TiO}_{2}$. Cristobalite was also found as isolated particles.

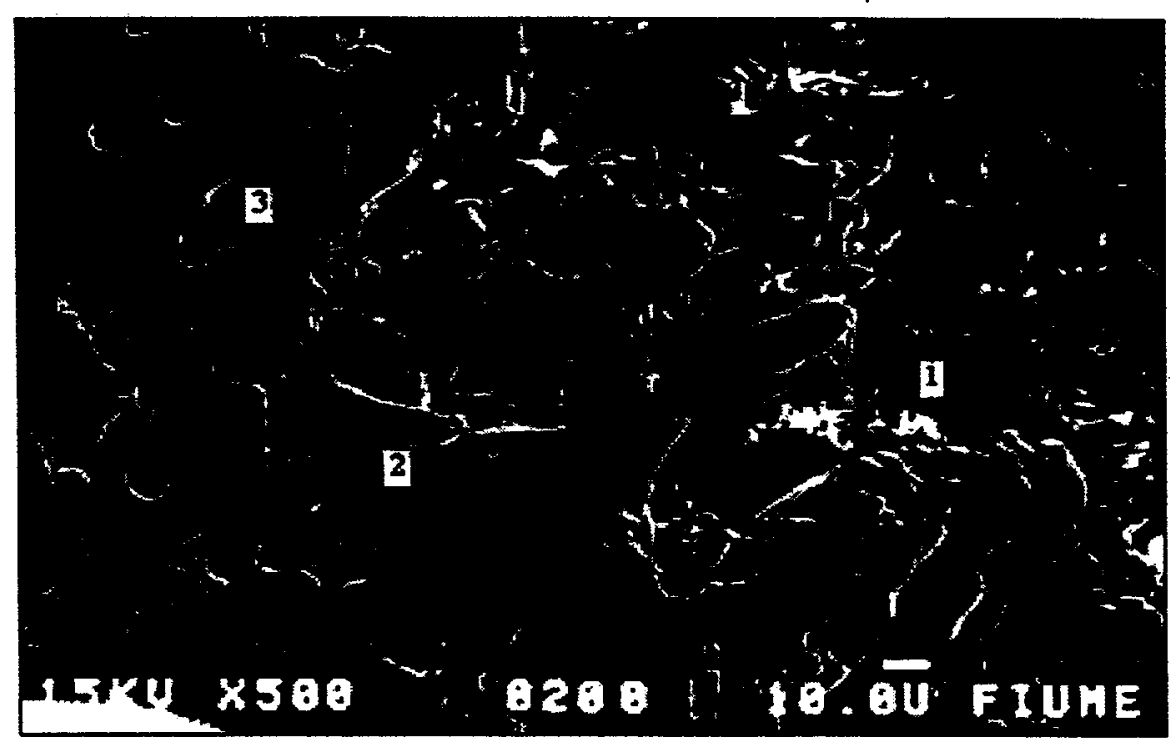

Figure 16. Complex morphology within a pore in the surface layer (tailing pond material, $1550^{\circ} \mathrm{C}$ ).

\section{Capping Material}

Two distinct layers were observed in the sintered capping material pellets, as shown in Figure 17. The surface layer contained corundum with some $\mathrm{Nb}, \mathrm{Zr}$, and $\mathrm{Ti}$ impurities. The core consisted of mullite with similar impurities. The composition of the cracked surfaces was similar to that of the surface layer. Particles on the cracked surface were composed of $\mathrm{Si}, \mathrm{Al}, \mathrm{Fe}, \mathrm{Ti}$, and $\mathrm{Nb}$. 


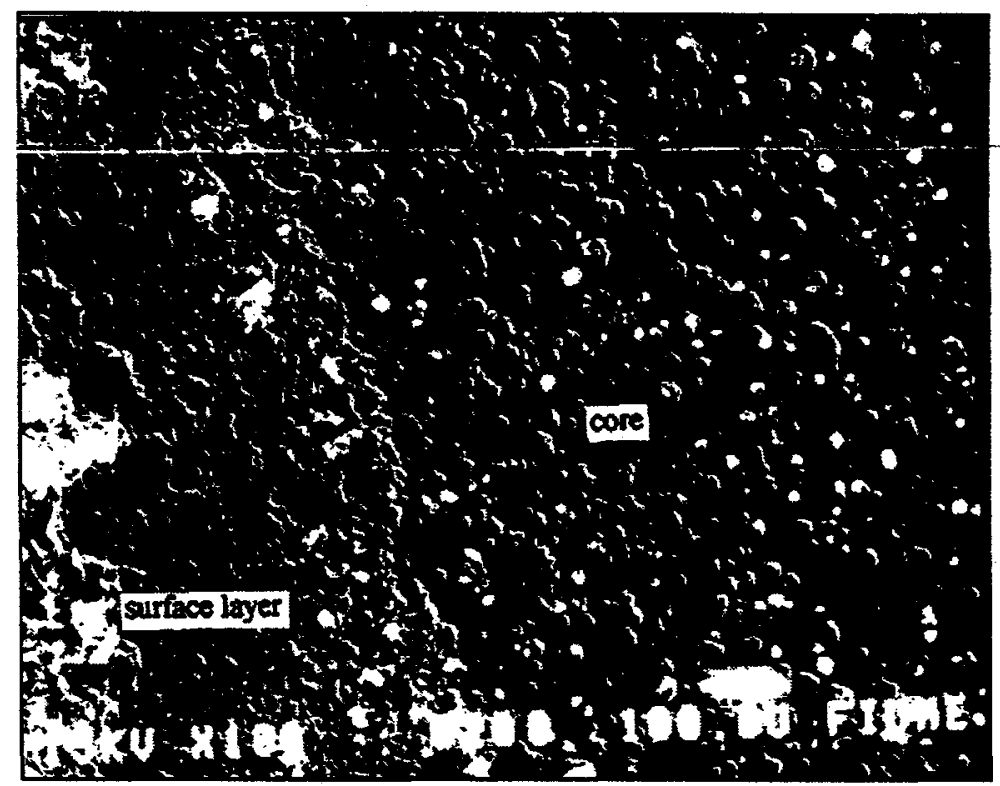

Figure 17. Two layers in the capping material sintered at $1550^{\circ} \mathrm{C}$.

\subsubsection{Conclusions}

Based on the examination by SEM and EDAX, the following conclusions have been drawn:

1. Raw bauxite contains a significant amount of $\mathrm{TiO}_{2}$, which segregates during firing. On the other hand, tailing pond material contains a significant amount of $\mathrm{SiO}_{2}$, which results in isolated cristobalite particles at $1450^{\circ}$ and $1550^{\circ} \mathrm{C}$. The metals $\mathrm{Nb}$ and $\mathrm{Zr}$ were detected only in the capping material;

2. All pellets crack extensively when fired at $1550^{\circ} \mathrm{C}$. Corrundum is observed to be present mainly on the surface of the pellets and on the surface of the cracks. However, the core is found to be composed of mullite;

3. $\mathrm{TiO}_{2}$ is detected in the corundum and mullite phases of all fired samples. Impurities of $\mathrm{Ti}, \mathrm{Fe}$, $\mathrm{V}, \mathrm{Nb}, \mathrm{Zr}, \mathrm{Mg}, \mathrm{Na}, \mathrm{K}, \mathrm{Ca}, \mathrm{Cl}$, and $\mathrm{Cr}$ are found to segregate on the pore surface or as particles on the surface of cracks; and

4. The segregation of impurity metals during the sintering of the pellets serves as a precursor for the mobilization of uranium during microwave sintering. 


\section{MAJOR FY96 ACCOMPLISHMENTS}

During FY96, we have conducted the investigation of the sintering of different bauxite extrudates in a conventional furnace in a helium atmosphere and in air for one hour and four hours at $1450^{\circ}$, $1550^{\circ}, 1650^{\circ}$, and $1750^{\circ} \mathrm{C}$. The physical properties, morphological microstructure, and the mineral composition after firing were evaluated and analyzed. The temperature dependence of the characteristics has been examined. The major accomplishments of FY96 work include the following:

- The acquisition of four types of bauxite extrudates-raw bauxite; traditional bauxite; tailing pond material, and capping material - from Guyana Linmine, Inc.;

- The determination of apparent porosity, specific gravity, volume contraction, and weight loss upon the sintering of the bauxite extrudates;

- EDAX analysis of the elemental composition of the raw materials, calculation of the chemical composition of the raw materials, and the identification of the mineralogical

- composition in the raw materials;

- Sintering of the bauxite extrudates at $1450^{\circ}, 1550^{\circ}, 1650^{\circ}$, and $1750^{\circ} \mathrm{C}$ in a traditional furnace under a helium atmosphere for one and four hours;

- Examination of the morphology of the sintered extrudates using scanning electron microscopy (SEM) and analysis of the elemental composition of micro-areas using X-ray energy dispersive analysis by (EDAX);

- Quantitative determination of the mineralogical composition of the sintered extrudates using powder X-ray diffraction analysis (XRD); and

- Shipping of the extrudates to Lambda Technologies to be fired in a variable frequency microwave furnace. 
Chu, M.C., Sato, S., Kobayashi, Y., and Ando, K. 1995, "Damage, Healing, and Strengthening Behavior in Intelligent Mullite/SiC Ceramics," Fatigue and Fracture of Engineering Materials and Structures, 18, pp. 1019-1029.

Everleigh, C.A., Johnson, A.C., Espinosa, R.J., and Garard, R.S., 1996, personal communication.

Fan, X., 1980, X-Ray Diffraction in Physical Metallurgy, Mechanical Industry Press, Beijing, p. 114.

Grimshaw, R.W., 1971, The Chemistry and Physics of Clays, Forth Edition, Ernest Benn Limited, London, p. 712.

Hamano, K., Nakajima, H., Okuda, F., and Konuma, M., 1994, "Preparation of Mullite Ceramics from Kaolin and Aluminous Materials (Part 1)," Journal of the Ceramic Society of Japan, International Edition, 102(1), pp. 80-85.

Kobayashi, Y., Li J., Kawasaki, A., and Watanabe, R., 1996, "Microstructure and HighTemperature Property of Reaction HIP-Sintered SiC-AIN Ceramic Alloys," Materials Transactions, JM, 37(4), pp. 807-812.

Liu, K.C., Thomas G., Caballero, A., Moya, J.S., and Aza, S. D., 1994, "Mullite Formation in Kaolinite - $\alpha$-Alumina," Acta Metallurgical et Materialia, 42(2), pp. 489-495.

Messler, R.W. Jr., 1995, "Joining Advanced Materials," Advanced Materials and Processes, $147(2)$, p. $47-49$.

Moore, J.J., Ready, D.W., Feng, H.J., Monroe, K., and Mishra, B., 1994, "The Combustion Synthesis of Advanced Materials," Journal of Metals, 46(11), pp. 72-78.

Munir, Z.A. and Tamburini, U.A., 1989, "Self-Propagating Exothermic Reactions: the Synthesis of High-Temperature Materials by Combustion," Materials Science Reports, 3, pp. 227365 .

Munroe, N.D.H., 1977, "Manufacture of a Variety of Grogs from Guyan Aluminosilicates," thesis, University of Leeds.

Musil, J., 1996, "Deposition of Thin Films Using Microwave Plasma: Present Status and Trends," Vacuum, 47(2), pp. 145-155.

Rudder, R.A., Hendry, R.C., Hudson, G.C. and Markunas, R.J., 1993, "Diamond Chemical Vàpor Deposition (CVD) via Microwave-Excited Plasma from Water-Ethanol Solutions," Ceramic Transactions, The American Ceramic Society, Vol. 36, pp. 377-384.

Saltiel, C., Fathi, Z. and Sutton, W., 1995, "Materials Processing With Microwave Energy," Mechanical Engineering, 117(8), pp. 102 -105.

Sutton, W.H., 1989, "Microwave Processing of Ceramic Materials," Ceramic Bulletin, 68(2), pp. $376-386$. 



\title{
Publication Derived from this Research \\ (Submitted to the Journal of the American Ceramic Society)
}

\author{
AGGREGATES FOR THE MONOLITHIC INDUSTRY
}

by

\author{
Dr. Norman D. H. Munroe* \\ Assistant Professor \\ Mechanical Engineering Department \\ Florida International University \\ University Park Campus \\ Miami, FL 33199, USA
}

*Member, American Ceramic Society 


\begin{abstract}
Various compositions of slightly beneficiated kaolin and bauxite have been prepared and fired at temperatures ranging from $1200^{\circ}$ to $1700^{\circ} \mathrm{C}$. Physical properties including porosity, true specific gravity, cold-crushing strength and mullite content have been determined and compared to the properties of commercially available refractory aggregates. A mullite content of 95 percent developed in mixes of high alumina content when these were fired at $1600^{\circ} \mathrm{C}$. Such aggregates displayed low porosity and superior cold-crushing strength.
\end{abstract}




\section{INTRODUCTION}

Preliminary investigations have revealed that kaolin and bauxite could be blended into high quality refractory mixes which, upon firing, produce a dense, low porosity refractory aggregate that can be made to various specifications. ${ }^{1}$ The bauxite normally used for refractory purposes often contains more than 65 percent $\mathrm{Al}_{2} \mathrm{O}_{3}$, less than 2 percent $\mathrm{SiO}_{2}$, less than 2 percent $\mathrm{Fe}$, but it may also contain less $\mathrm{Al}_{2} \mathrm{O}_{3}$. The precambrian Guyana Shield that extends over an area that encompasses French Guyana, Surinam, Guyana, and Brazil on the NorthEastern tip of the South American continent is said to contain over 400 million tons of bauxite. $^{2,3}$ In many cases, kaolin, which is conducive to the synthesizing of mullite based aggregates, is found at the base and/or above the bauxite stratum.,5

Due to escalating labor costs and requirements for extended performance, the conventional brick furnace lining has been replaced to a considerable extent by monolithic structures which are rammed, gunned, or cast into position. Thus, a variety of grogs ranging in $\mathrm{Al}_{2} \mathrm{O}_{3}$ content from approximately 45 to 80 percent can be manufactured using these aluminosilicate raw materials. In most cases, prefired calcines are of controlled qualities and are used in moldable and castable compositions.

In castables, the aggregate is mixed with other granulated refractory materials, and a suitable hydraulic setting agent is added. This mix is then combined with water and either poured or cast into shape. Ramming mixes, or moldables, consist of aggregate mixed with other granulated refractory materials, plastic clays, and a self-bonding agent. The mixture is rammed into place to form-a dense and strong refractory structure upon heating.

Aggregates are employed in super-duty, high alumina bricks, which have high refractoriness, strength, and stability of volume at high temperatures. Such properties are 
required primarily due to the practice of utilizing tailor-made grogs with better quality binders instead of using highly refractory calcined bauxite and low melting binders. Considering that the availability of established varieties of clays is now in question, a great demand exists for high quality grogs, especially in the iron, steel, carbonizing, and aluminum industries.

\section{EXPERIMENTAL PROCEDURES}

The raw materials used in this investigation were comprised of two slightly beneficiated clays found in Guyana. Bauxite lumps were crushed using a laboratory jaw crusher, and the sieve fraction less than 150 micron $(-150 \mu \mathrm{m})$ was collected and stored. The oversized fraction was ground wet in a ceramic ware ball mill. The resulting slurry was subjected to differential sedimentation $^{6}$ to obtain a fraction composed of -10 micron particles. The same procedure was adopted to obtain -150 micron and -10 micron kaolin materials.

The materials were weighed and mixed together so that the total $\mathrm{Al}_{2} \mathrm{O}_{3}$ content in the various mixes was $50,60,70$, and 80 percent, respectively, on a calcined basis. Water was added to approximately 10 grams of bauxite and clay prior to compaction (about 4 percent by weight for low alumina mixtures, increasing to about 8 percent by weight for calcined bauxite). Test specimens in the form of discs 38 millimeters $(\mathrm{mm})$ in diameter and about 4.5 $\mathrm{mm}$ thick were prepared using a manually operated ring press at a pressure of $78.4 \mathrm{MN} \mathrm{m}^{-2}$. Each specimen was then weighed and measured before undergoing the preheat treatment. Specimens ranging in $\mathrm{Al}_{2} \mathrm{O}_{3}$ content from 44 to 88 percent on a calcined basis were prepared and fired to a temperature ranging from $1200^{\circ}$ to $1700^{\circ} \mathrm{C}$.

Preheating consisted of simulating the basic principle of a humidity dryer, where specimens were placed in an airtight vessel containing a small amount of water. The 
temperature was raised to $70^{\circ} \mathrm{C}$ in an airtight vessel and maintained for 24 hours. This reduced the variation in water content and pressure variations within the specimens, thereby reducing the risk of cracking or distortion upon firing. Subsequently, all samples were heated very slowly to $900^{\circ} \mathrm{C}$ at a firing rate of $20^{\circ} \mathrm{C} /$ minute and held there for 24 hours. The samples were then sintered at various temperatures, including $1200^{\circ}, 1300^{\circ}, 1400^{\circ}, 1500^{\circ}, 1600^{\circ}$, and $1700^{\circ} \mathrm{C}$. The experimental flow chart for the firing of the aluminosilicate mixes is illustrated in Fig. 1.

\section{SINTERING AND FORMATION OF MULLITE}

Corrundum $\left(\alpha-\mathrm{Al}_{2} \mathrm{O}_{3}\right.$ ) is formed by heating aluminosilicate mixtures with over 75 . weight percent of $\mathrm{Al}_{2} \mathrm{O}_{3}$ to temperatures in excess of $1400^{\circ} \mathrm{C}$. Mullite is a stable, intermediate solid- solution phase present in aluminosilicate systems. ${ }^{7,8,9}$ The reaction of alumina and silica to produce mullite can be very slow if corundum is formed. ${ }^{10,11,12}$ A slow heating rate was therefore employed in the present investigation to enhance liquid formation, which is known to increase the growth of the mullite phase. Crystal growth and liquid formation depend on factors such as composition; grain-size and distribution of materials; firing rate; and the duration of the maximum temperature. The liquid produced may dissolve some of the crystal formed by the solid reaction process, and, conversely, some liquid may crystallize on contact with the solid as a result of the change in composition or the "seeding" of the cooling phase. These processes are catalyzed by impurities and may lead to increased vaporization, diffusion, and lowering of the glass phase viscosity, thus causing the liquid phase formed from impurities in the aluminosilicate material to "wet" the particles more readily. The effect of the impurities, however, is considerably reduced if the $\mathrm{Al}_{2} \mathrm{O}_{3}$ is converted to the relatively inert corundum. 


\section{RESULTS AND DISCUSSION}

Sintering shrinkage was obtained by measuring the diameter and thickness of each specimen with a micrometer screw gauge before and after firing to determine the change in volume. The specimens were sufficiently precise in shape for this procedure to be acceptable. Errors due to irregularities in the shape of the specimens were overcome by taking the average of several readings. The difference in volume, when expressed as a percentage of the original volume, constituted the volume shrinkage.

Greater firing shrinkage at specific temperatures was observed in specimens made from finer materials ( -10 micron) than in specimens -150 micron in particle size (see Fig. 2). Shrinkage commenced at $550^{\circ}$ and $350^{\circ} \mathrm{C}$ for kaolin and bauxite, respectively, and continued at a fairly even rate. As the temperature increased, dense crystals of mullite, corundum, and cristobalite developed, with a consequent reduction in pore space. Contraction was the inevitable result of the increased density of these phases. However, the amount of volume shrinkage that occurred and its rate of development depended on particle size, composition, and the duration of firing.

The initial shrinkage in each case showed a similar trend up to roughly $1400^{\circ} \mathrm{C}$. At higher temperatures, specimens with high $\mathrm{Al}_{2} \mathrm{O}_{3}$ content $(60,70$, and 80 percent) became virtually stable in volume as illustrated by the plateau on those curves shown in Fig. 2. Specimens low in $\mathrm{Al}_{2} \mathrm{O}_{3}$ content indicated a slight expansion in volume at temperatures above $1600^{\circ} \mathrm{C}$. This was probably due to bloating caused by trapped gases in the glassy phase. ${ }^{9}$ This phenomenon suggests greater liquid formation at temperatures above $1600^{\circ} \mathrm{C}$ in the mixes composed of -10 micron particles. Less bloating occurred in mixes composed of coarsegrained particles (-150 micron). 
A number of theories have been suggested to account for firing shrinkage when a glassy phase develops. The stretched-membrane theory ${ }^{7,8}$ proposed for drying shrinkage suggests shrinkage forces result from the presence of a glassy phase in the capillaries. In general, permanent changes in volume are found to be due to 1) the decomposition and removal of some constituents; 2) the formation of other allotropic forms of the same material, which results in a change of specific gravity, and consequently, either volume expansion or contraction; 3) a chemical reaction, producing a new material of greater specific gravity with a consequent volume reduction; 4) the formation of a liquid phase, which flows into and fills some of the original pore space; and 5) sintering reactions, which also result in a decrease in pore space and an overall volume reduction. Changes in volume are often of great technical importance, especially when materials that undergo such changes are used to make articles of a definite size within very narrow specifications.

Weight loss was found by comparing the weight of each specimen before it was fired to the weight after firing. The loss was expressed as a percentage of the original weight. Figure 3 illustrates a weight loss of 14 percent for the kaolin specimens. This loss results from the decomposition of kaolinite $e^{11}$ that occurs at roughly $585^{\circ} \mathrm{C}$. The slight increase in percentage weight loss at temperatures in excess of $1200^{\circ} \mathrm{C}$ is attributed to the decomposition of small amounts of impurities, such as carbonates or sulfates, which occurs at these temperatures.

The gradual increase in weight loss with the $\mathrm{Al}_{2} \mathrm{O}_{3}$ content resulted from the increase in bauxite content, which had 30 percent of combined water. Thus, those specimens with a high content of this ingredient demonstrated a corresponding higher loss in weight. For the purpose of mineral accountancy, it is imperative that data concerning weight loss at processing temperatures be available, particularly in the heat treatment of materials that possess water 
molecules of hydration.

Apparent porosity was evaluated by a modified version of the British Standard Evaluation Method ${ }^{11}$, in which water is used to penetrate and displace the air within the specimens. Fine-grained specimens, having a large surface factor, were found to have higher porosities up to $1400^{\circ} \mathrm{C}$ than mixes composed of -150 micron particles. This was in accordance with the established fact that mixtures of fine materials are often more porous than mixtures of coarse materials because of difficulties in packing in the raw state. However, above $1400^{\circ} \mathrm{C}$, the fine-grained specimens showed a remarkable reduction in porosity to virtually zero at temperatures between $1550^{\circ}$ and $1650^{\circ} \mathrm{C}$. The coarse-grained specimen developed greater porosity at these higher temperatures (see Fig. 4).

At high temperatures, small-grained particles fused more readily than coarse-grained particles due to enhanced reaction rates. The liquid formed filled the interstices and voids, resulting in a reduction of porosity. An increase in the $\mathrm{A}_{2} \mathrm{l}_{2} \mathrm{O}_{3}$ content of the specimen resulted in an increase in the temperature at which zero porosity was attained.

The development of a liquid phase was not the only factor for the reduction of porosity. Crystal growth which occurred at $1500^{\circ} \mathrm{C}$ and above resulted in a large decrease in porosity due to the appearance of new crystalline minerals, especially on prolonged heating. Void space within the bodies is reduced by a physical process involving solid state reactions, which increase in activity as the temperature is further raised or maintained. At high temperatures, around $1500^{\circ} \mathrm{C}$ and above, the fine-grained specimens with an $\mathrm{Al}_{2} \mathrm{O}_{3}$ content of 70 percent and over showed a decrease in porosity. As previously mentioned, this may be attributed to liquid formation, which fills interstiticial sites. This phenomena is predominant over the effect void spaces created by the evolution of volatile matter and the effect of mullite formation, which is 
accompanied by volume expansion that may produce voids.

An increase in the $\mathrm{Al}_{2} \mathrm{O}_{3}$ content resulted in an increase in the porosity of the specimens (see Fig. 5). In general, the porosity of a mass increases if it contains components which volatilize, evaporate, or decompose with the liberation of gases. The removal of structural water, which causes rearrangements in the lattice, is also known to increase porosity. These phenomena therefore account for the increase in the porosity of specimens having increasing amounts of bauxite $\left(\mathrm{Al}_{2} \mathrm{O}_{3} \cdot 3 \mathrm{H}_{2} \mathrm{O}\right)$. The ability of materials to sinter to a mass of low porosity is of particular value in the manufacture of castable and moldable compositions. If grog of virtually zero porosity is incorporated, it cannot shrink further in service; furthermore, it is remarkably resistant to slag and metal penetration as well as to erosion.

True specific gravity is the average value of the true density of the new minerals formed on firing. The minerals present in the compacts either decomposed and then recrystallized or recombined with other components to form entirely different minerals, such as mullite, cristobalite, corundum, or glassy phase, all of which have different specific gravities as compared to the initial components. Figure 6 shows the variation of the true specific gravity of the fired products resulting from different sintering conditions. In general, a higher sintering temperature and an increase of $\mathrm{Al}_{2} \mathrm{O}_{3}$ content produced grogs of a higher density, the effect of the latter being more profound. The compacts differed in specific gravity on account of variations in their composition and structure at various temperatures. The new minerals formed upon firing kaolin, bauxite, and mixtures of both are described elsewhere. ${ }^{11,13}$ If the proportion of each new mineral formed could have been deduced, then the average specific gravity could have been calculated by taking the arithmetic mean of the components. 
Kaolinite (45 percent $\mathrm{Al}_{2} \mathrm{O}_{3}$ on a calcined basis), for example, has a specific gravity of 2.615. Upon heating, it dissociated, finally forming mullite (specific gravity, 3.03) and cristobalite (specific gravity, 2.32) in accordance with Eq. (1) shown below. From the ratio of the weights of mullite and cristobalite in the fired product, the final specific gravity should theoretically be 2.77 . However, the results obtained in these experiments were derived as a result of the following reactions and/or combinations of each. The formation of appreciable amounts of glass and other side reactions also played an important role.

$$
\begin{array}{ccr}
3\left(\mathrm{Al}_{2} \mathrm{O}_{3} \cdot 2 \mathrm{SiO}_{2} .2 \mathrm{H}_{2} \mathrm{O}\right) & 3 \mathrm{Al}_{2} \mathrm{O}_{3} \cdot 2 \mathrm{SiO}_{2}+4 \mathrm{SiO}_{2}+6 \mathrm{H}_{2} \mathrm{O} \\
\text { (Kaolinite) } & \text { (Mullite) } \\
& \text { (Cristobalite) } \\
\mathrm{XAl}_{2} \mathrm{O}_{3}+3 \mathrm{Al}_{2} \mathrm{O}_{3} \cdot 2 \mathrm{SiO}_{2}= & (3+\mathrm{X}) \mathrm{Al}_{2} \mathrm{O}_{3} .2 \mathrm{SiO}_{2}
\end{array}
$$

(Higher alumina content mullite)

$$
\begin{array}{r}
3 \mathrm{Al}_{2} \mathrm{O}_{3}+2 \mathrm{SiO}_{2}=\quad 3 \mathrm{Al}_{2} \mathrm{O}_{3} \cdot 2 \mathrm{SiO}_{2} \\
\text { (Mullite) }
\end{array}
$$


formed according to Eq. (2). Higher diversities were attained in specimens fired from finegrained materials than from coarse-grained materials. The increase of specific gravity with $\mathrm{Al}_{2} \mathrm{O}_{3}$ content was also more pronounced in specimens fired from fine-grained materials (see Fig. 6).

Mullite was determined quantitatively by an internal standard technique. ${ }^{14}$ The mullite content of the sintered specimens increased with sintering temperature and with $\mathrm{Al}_{2} \mathrm{O}_{3}$ content. More mullite was formed in compacts from fine-grained materials than from coarse-grained materials. Less mullite was formed in compacts that contained the relatively more impure Ituni Kaolin material. A low mullite content was determined in compacts fired at $1200^{\circ} \mathrm{C}$, but these low values may also be attributed to poor peak intensity for the mullite phase determination by $x$-ray diffraction.

Theoretical values were approached in the sintering of the raw kaolin materials (see Fig.7). According to the reaction expressed in Eq. (1), the theoretical composition of sintered kaolinite is 64.0 percent mullite by weight and 36.0 percent crystobalite by weight. ${ }^{15,16}$ The result obtained indicated that the kaolin materials were of excellent quality and could be used âs grogs (chamotte) on their own. The decrease in the amount of muliite formed in compacts containing 80 percent $\mathrm{Al}_{2} \mathrm{O}_{3}$ was probably due to the high content of bauxite in the mix. The phase diagram presented by Aramaki and Roy ${ }^{7,8}$ indicates that corundum and mullite are formed at high $\mathrm{Al}_{2} \mathrm{O}_{3}$ content.

Less mullite was formed in compacts made from the bauxite/Ituni clay mix as compared to the bauxite/Topira clay mix. This may be attributed to the formation of large amounts of glass due to higher impurities and the less ordered kaolinite constituent in the latter as compared to the Topira clay sample. The higher surface energy of fine-grained materials (- 
10 micron) resulted in a higher mullite content in sintered compacts than those made from coarse-grained materials (-150 micron).

Previous experiments conducted on mixes of bauxite and kaolin indicated that substantial amounts of free corundum remained in compacts fired up to $1600^{\circ} \mathrm{C}$, indicating that equilibrium was not approached. However, smaller amounts of free corundum were recorded in compacts heated to $1700^{\circ} \mathrm{C}$. It was therefore concluded that the free corundum was used up by either or both of reactions shown in Eqs. (2) and (3). Considering the impurity content of bauxite and kaolin, a fair amount of glass formation was anticipated at high temperatures, and the reaction of Eq. (3) was more likely to be predominant.

Cold strength was determined using a modified British Standard method ${ }^{11}$ for measuring the modulus of rupture. A laboratory Instron machine was employed with an applied loading rate of $0.1 \mathrm{~cm} /$ minute. This test was used to determine cold crushing strength, degree of vitrification, flaws, and the purity of the material. The cold crushing strength of sintered kaolin/bauxite mixes at various conditions is shown in Fig. 8. In general, the cold crushing strength increased with temperature and with an increase in $\mathrm{Al}_{2} \mathrm{O}_{3}$ content. Sintered mixes of $\mathrm{Al}_{2} \mathrm{O}_{3}$ content greater than 60 percent possessed a crushing strength of between 160 $200 \mathrm{MPa}$ at $1600^{\circ} \mathrm{C}$ but less than $100 \mathrm{MPa}$ for mixes with an $\mathrm{Al}_{2} \mathrm{O}_{3}$ content below 60 percent (or consisting of coarse-grained particles [-150 micron]). Compacts containing 70 percent and 80 percent $\mathrm{Al}_{2} \mathrm{O}_{3}$ possessed greater crushing strength, but only at higher temperatures. The relatively high strengths observed in compacts consisting of up to 60 percent $\mathrm{Al}_{2} \mathrm{O}_{3}$ indicated that fusion occurred at lower temperatures. Topira kaolin mixes had greater crushing strength than the Ituni kaolin mixes. 
The cold crushing strength of the compacts varied according to the temperature at which they were fired and depended on the extent to which the particles bonded together with fused matter. In addition, factors such as the chemical and mineral composition of the materials, the physical properties of the materials, the variation in the mode of manufacture and firing conditions, affect the results. Mineralogical changes that occur upon sintering aluminosilicate mixes affected the cold crushing strength of compacts in a similar manner, as they did the true specific gravity and apparent porosity. Thus, they partly explain the variation of the cold crushing strength.

Tables I and II illustrate the properties of commercial aluminosilicate ramming mixes and castables from a Brazilian manufacturer. Table III compares the properties of refractory grogs ${ }^{13}$ that were prepared from kaolin-bauxite mixes from Guyana with electrofused mullite prepared from Brazilian raw materials. The $x$-ray diffraction pattern of a kaolin/bauxite mix $(-10$ micron particles, 70 percent $\mathrm{Al}_{2} \mathrm{O}_{3}$, fired at $1700^{\circ} \mathrm{C}$ ) is compared in Figs. 9 and 10 with that of a commercially available sintered mullite. 


\section{CONCLUSION}

Two kaolin samples from Guyana were blended with bauxite producing mixes of various $\mathrm{Al}_{2} \mathrm{O}_{3}$ content. The relatively pure Topira sample produced 63 percent mullite when sintered to $1700^{\circ} \mathrm{C}$ and a 95 percent mullite content when blended with bauxite (-10 micron). The less pure Ituni sample produced grogs of mullite content 62 and 89 percent, respectively, when sintered above $1700^{\circ} \mathrm{C}$ and blended with bauxite under the same conditions. The difference in mullite content was attributed to the level of impurities in the kaolin; too many impurities caused a breakdown in the formation of mullite crystals. 


\section{REFERENCES}

'S. Garret, M. Phil.Thesis, University of Leeds, U.K. (1977).

2B. Choubert, Bull. Soc. Geol. France, 1 [7], 129 -135 (1965).

${ }^{3}$ G. Doeve, Groeneveld and W. O. J. Meijer: Econ. Geol., 58 [7], 1160-1162 (1963).

${ }^{4}$ T. Van Der Hammen and T. A. Wymstra, Leidse Geol., Mededel., 30, 184-240 (1964).

5. H. Moses and W. D. Michel, Econ., Geol, 58, 250-262 (1963).

${ }^{6}$ N. Stanley-Wood, T.A. Allen, Proceedings of the Fourth Particle Analysis Conference, Loughborough University of Technology, 219-231 (1981).

${ }^{7}$ S. Aramaki and R. Roy, J. Am. Ceram. Soc., 42, 644 (1959).

${ }^{8}$ S. Aramaki and R. Roy, J. Am. Ceram. Soc., 45, 239 (1962).

${ }^{9}$ T.D. McGess and C. M. Dodd, J. Am. Ceram. Soc., 44, 277 (1961).

${ }^{10} \mathrm{~F} . \mathrm{H}$. Norton, Refractories, 4th edition (1994).

${ }^{11}$ R. W. Grimshaw, The Chemistry and Physics of Clays, 4th edition, 852-861 (1971).

${ }^{12}$ W. H. Hawkes, Trans. Brit. Ceram. Soc., 61, 689 (1962).

${ }^{13}$ N. D. H. Munroe, M. Phil. Thesis, University of Leeds, U.K. (1977).

${ }^{14}$ P. H. Kiug and L. E. Alexander, X-Ray Dif̂fraction Procedures, John Wiley \& Sons, Inc., 531-552 (1967).

15J. J. Comer, Bull. Am. Ceram. Soc., 43, 378 (1960).

${ }^{16}$ D. J. Stirland, A. G. Thomas and N. C. Moore, Trans. Brit. Ceram. Soc., 57, 69 (1958). 


\section{FIGURE CAPTIONS}

Figure 1. Experimental flow chart for the firing of aluminosilicate refractory grogs.

Figure 2. Sintering shrinkage of kaolin/bauxite mixes.

Figure 3. Percentage weight loss of sintered kaolin/bauxite mixes at various conditions.

Figure 4. The porosity of sintered kaolin/bauxite mixes at various conditions.

Figure 5. The porosity of kaolin/bauxite mixes vs $\mathrm{Al}_{2} \mathrm{O}_{3}$ content.

Figure 6. The variation of true specific gravity of sintered kaolin/bauxite mixes with $\mathrm{Al}_{2} \mathrm{O}_{3}$ content.

Figure 7. The percentage of mullite phase vs sintering condition and $\mathrm{Al}_{2} \mathrm{O}_{3}$ content.

Figure 8. The modulus of rupture for sintered kaolin/bauxite mixes at various conditions.

Figure 9. The results of $\mathbf{x}$-ray diffraction pattern analysis of a sintered mullite obtained commercially.

Figure 10. The results of $x$-ray diffraction pattern of a kaolin/bauxite mix $(-10 \mu)$ drypressed and sintered at $1700^{\circ} \mathrm{C}$. 
Table I.- Properties of Commercial Aluminosilicate Ramming Mixes

\begin{tabular}{ccccc}
\hline Brand Name & $\%$ & Bulk Density & Cold & Heated at \\
& $\mathrm{Al}_{2} \mathrm{O}_{3}$ & $\mathrm{Kg}^{3} \mathrm{~m}^{3}$ & $\begin{array}{c}\text { Crushing } \\
\text { Strength- } \\
\end{array}$ & $\begin{array}{c}\text { Kgf/cm } \\
\text { Dried at } \\
\end{array}$ \\
& & $\begin{array}{c}140^{\circ} \mathrm{C} \\
1100^{\circ} \mathrm{C}\end{array}$ \\
\hline
\end{tabular}

Aluminum Silicate - Ramming Mixes

Ranasil 40-QL

Ranasil AA

Ranasil 40-PC
42

42

44
2200

2100

2300
140

90

30
740

450

210

High Alumina-Ramming Mixes

\begin{tabular}{ll} 
Ranasil & $70-\mathrm{QL}$ \\
Ranasil & $70-\mathrm{QL}-\mathrm{FI}$ \\
Ranasil & $72-\mathrm{QL}$ \\
Ranasil & $804-\mathrm{QL}$ \\
Ranasil & $90-\mathrm{QL}$ \\
Ranasil & $90-\mathrm{QL}-\mathrm{E}$ \\
Ranasil & $898-\mathrm{QL}$ \\
Ranasil & 192 \\
Ranasil & 357 \\
\hline
\end{tabular}

67

55

72

70

90

84

95

94

95
2300

2300

2600

2400

3100

3000

3000

3000

3000
110

120

250

180

170

230

210

38
190

250

450

350

650

450

580

680 
Table II. Properties of Commercial Aluminosilicate Castables

\begin{tabular}{|c|c|c|c|c|c|c|c|}
\hline Brand Name & $\begin{array}{c}\% \\
\mathrm{Al}_{2} \mathrm{O}_{3}\end{array}$ & $\begin{array}{c}\% \\
\mathrm{Al}_{2} \mathrm{O}_{3}\end{array}$ & $\begin{array}{c}\text { Service } \\
\text { Limit } \\
\left.{ }^{\circ} \mathrm{C}\right)\end{array}$ & $\begin{array}{c}\text { Bulk } \\
\text { Density } \\
\mathbf{K g} / \mathbf{m}^{3}\end{array}$ & $\begin{array}{c}\text { Water } \\
\text { Required } \\
\text { L/100 Kg }\end{array}$ & $\begin{array}{c}\text { Cold } \\
\text { Crushing } \\
\text { Strength- } \\
\text { Kgt/cm } \\
\text { Dried at } \\
1100^{\circ} \mathrm{C} \\
\end{array}$ & $\begin{array}{c}\text { Heated } \\
\text { at } \\
1200^{\circ} \mathrm{C}\end{array}$ \\
\hline \multicolumn{8}{|c|}{ Aluminosilicate-Castables } \\
\hline Brasilcast 3810 & 35 & 2.5 & 1200 & 2000 & $14-19$ & 65 & - \\
\hline Brasilcast 4012 & 38 & 2.5 & 1300 & 2000 & $16-19$ & 68 & 180 \\
\hline Brasilcast 4014 & 43 & 1.8 & 1430 & 2100 & $11-15$ & 180 & 240 \\
\hline Brasilcast 4514 & 45 & 1.6 & 1430 & 2100 & $15-20$ & 130 & 230 \\
\hline \multicolumn{8}{|c|}{ High Alumina-Castables } \\
\hline Brasilcast 5014 & 58 & 1.5 & 1450 & 2200 & $12-14$ & 80 & 180 \\
\hline Brasilcast 6015 & 58 & 1.5 & 1480 & 2250 & $12-14$ & 110 & 280 \\
\hline Brasilcast 7016 & 68 & 1.8 & 1540 & 2300 & $10-15$ & 140 & 210 \\
\hline Brasilcast 7416 & 72 & 1.2 & 1600 & 2300 & $11-14$ & 120 & 230 \\
\hline Brasilcast 8516 & 85 & 1.0 & 1630 & 2750 & $10-13$ & 130 & 210 \\
\hline Brasilcast 9017 & 90 & 1.0 & 1680 & 3000 & $9-11$ & 150 & 280 \\
\hline Brasilcast 9517 & 93 & 0.7 & 1720 & 3100 & $9-11$ & 180 & 290 \\
\hline Brasilcast 9518 & 95 & 0.5 & 1750 & 3100 & $8-10$ & 210 & 350 \\
\hline Brasilcast 9515 & 95 & 0.5 & 1500 & 3100 & $8-10$ & 250 & 400 \\
\hline
\end{tabular}


Table III. Comparison of Electrofused Mullite and Grogs from Kaolin-Bauxite Mixes

\begin{tabular}{lccccc}
\hline $\begin{array}{l}\text { Brand } \\
\text { Name }\end{array}$ & $\begin{array}{c}\text { \% } \\
\mathbf{A l}_{2} \mathbf{O}_{\mathbf{3}}\end{array}$ & $\begin{array}{c}\text { \% Apparent } \\
\text { Porosity }\end{array}$ & $\begin{array}{c}\text { Bulk Density } \\
\mathbf{K g} / \mathbf{m}^{3}\end{array}$ & $\begin{array}{c}\text { Cold Crushing } \\
\text { Strength- } \\
\mathbf{K g g}_{\mathbf{c m}}\end{array}$ & $\begin{array}{c}\text { Modulus of } \\
\text { Rupture } \\
\mathbf{K g} / \mathbf{c m}^{2}\end{array}$ \\
\hline Brasmul 72 & 73 & 16 & 2.4 & 600 & 180 \\
Brasmul 100 & 75 & 19 & 2.4 & 350 & 95 \\
*Guyana $70^{*}$ & 70 & 20 & 3.1 & 807 & - \\
*Guyana 80 & 80 & 16 & 3.5 & 468 & - \\
\hline
\end{tabular}

* Sintering Temperature, $1500^{\circ} \mathrm{C}$ Blend of Topira Kaolin \& Bauxite (-10 micrometer) 


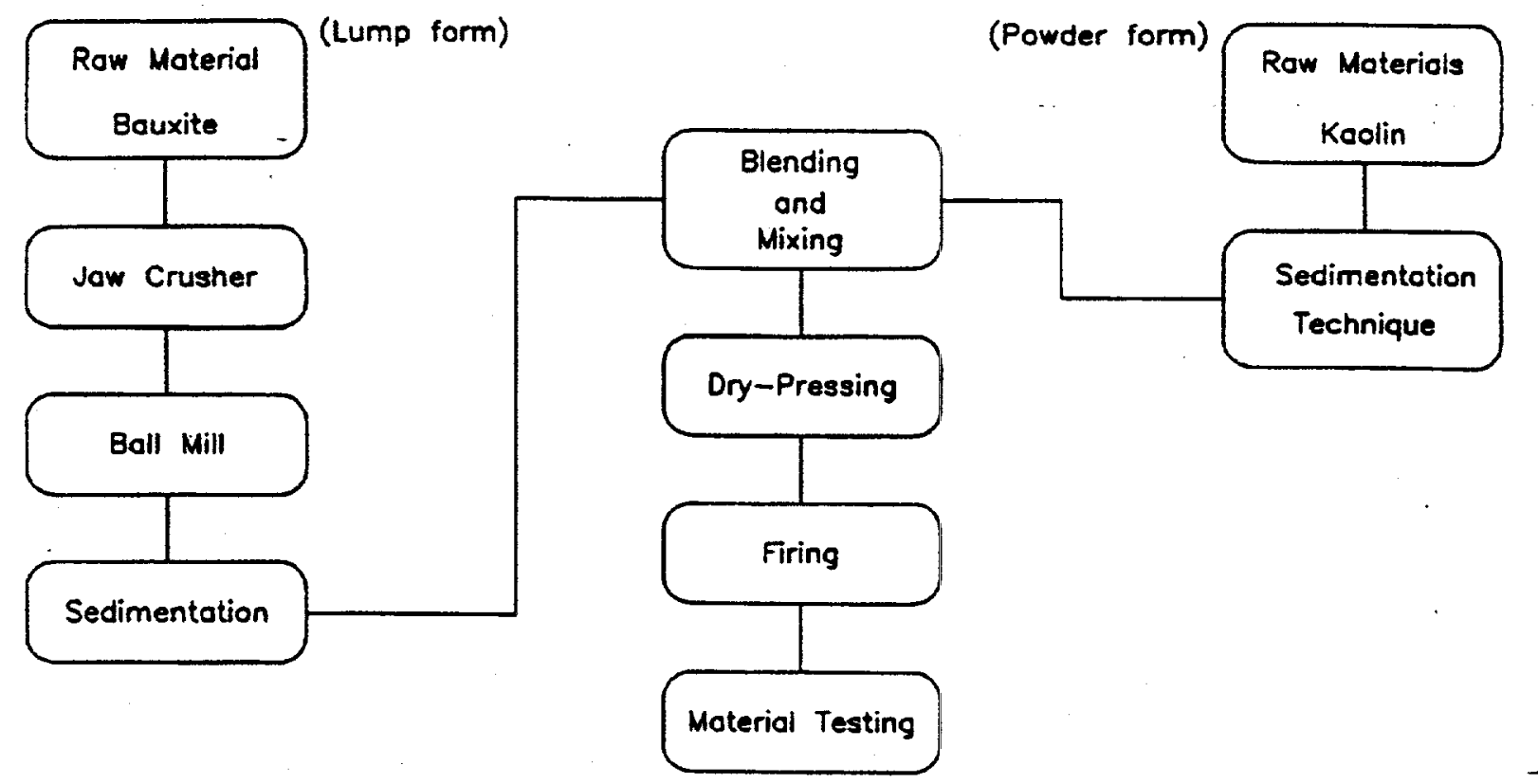

Figure 1 - Experimental flow chart for the firing of Alumino-Silicate refroctory grogs. 


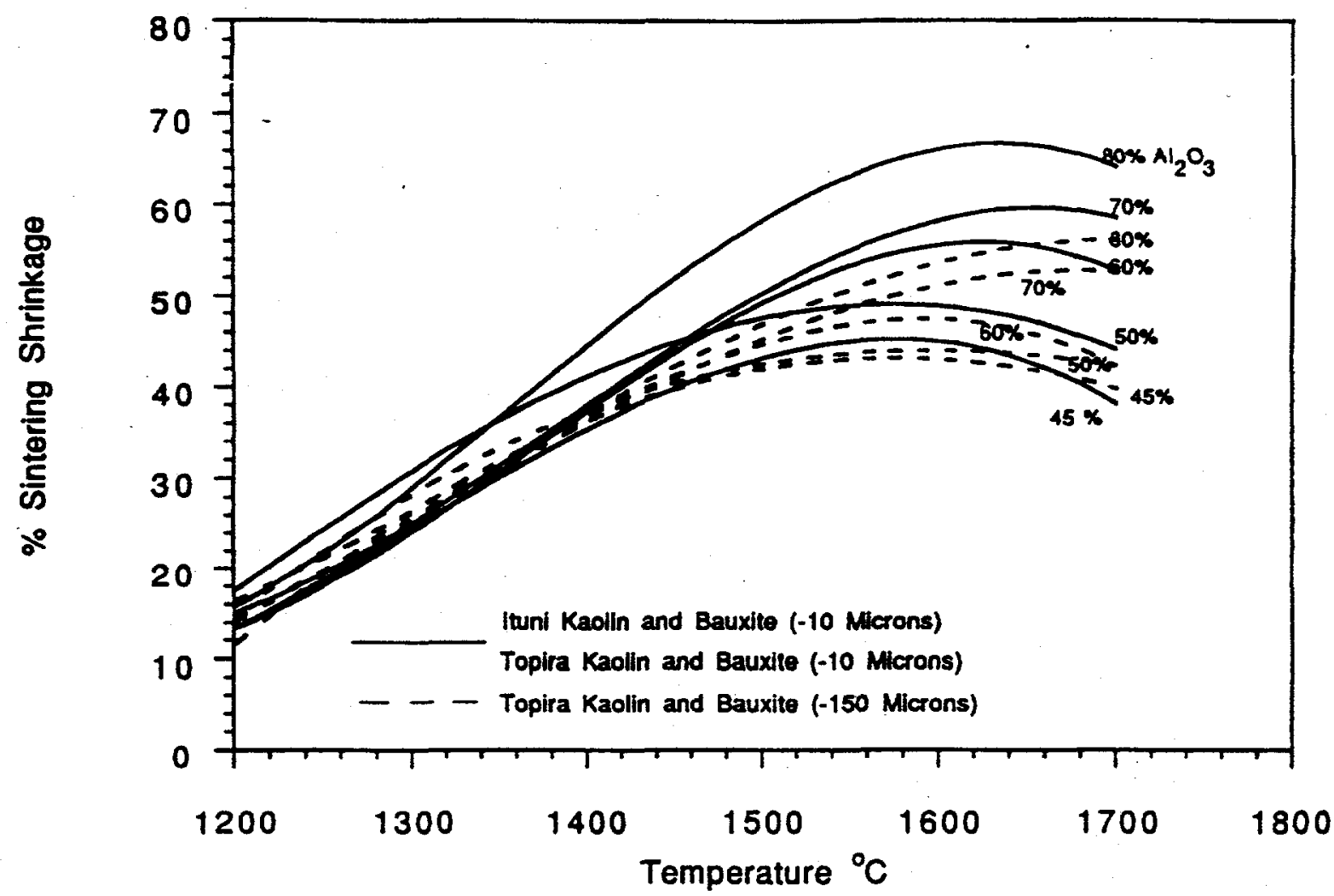

Figure 2 - Sintering shrinkage of kaolin/bauxite mixes. 


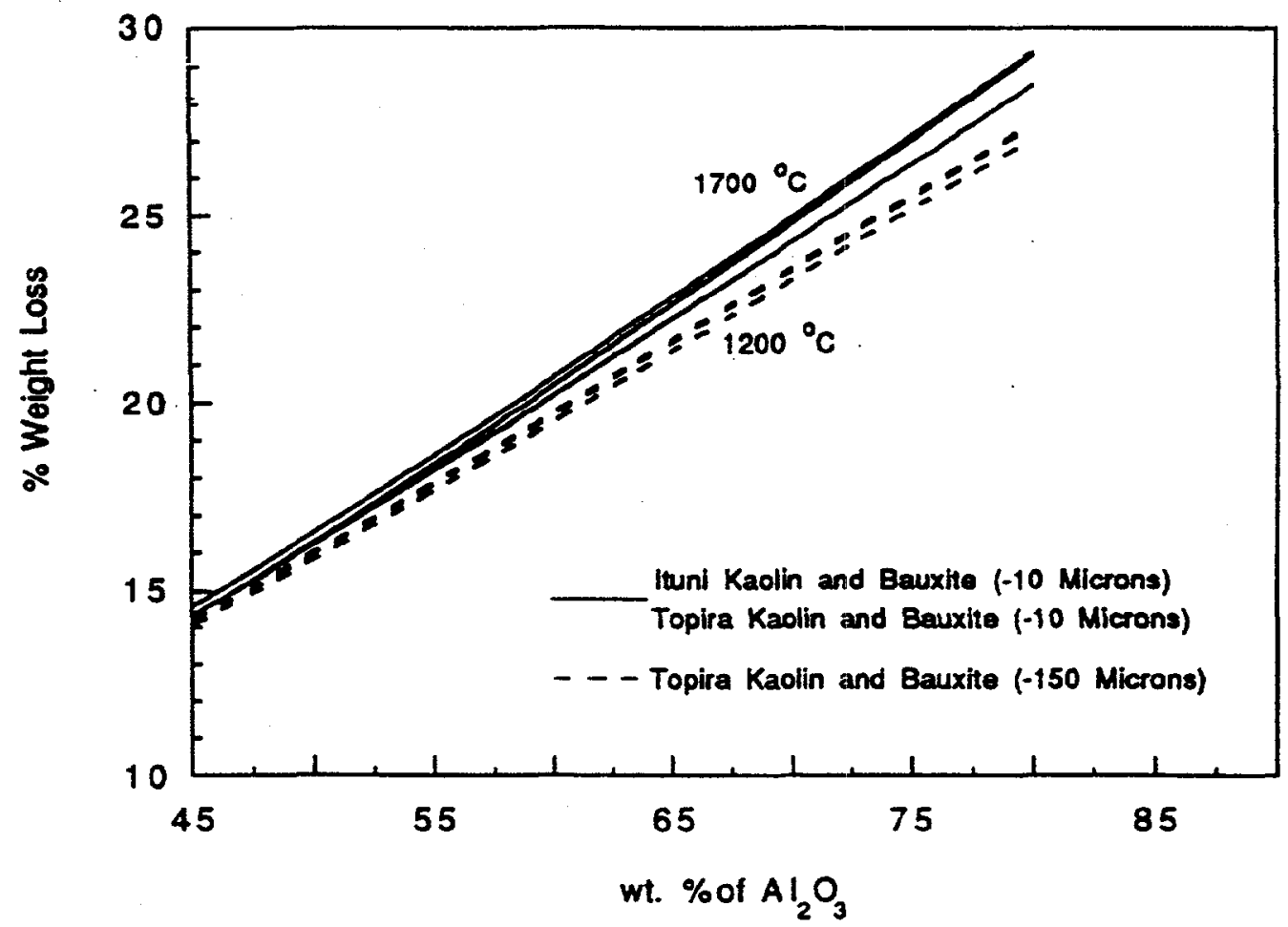

Figure 3 - Percentage weight loss of sintered kaolin/bauxite mixes at various conditions. 


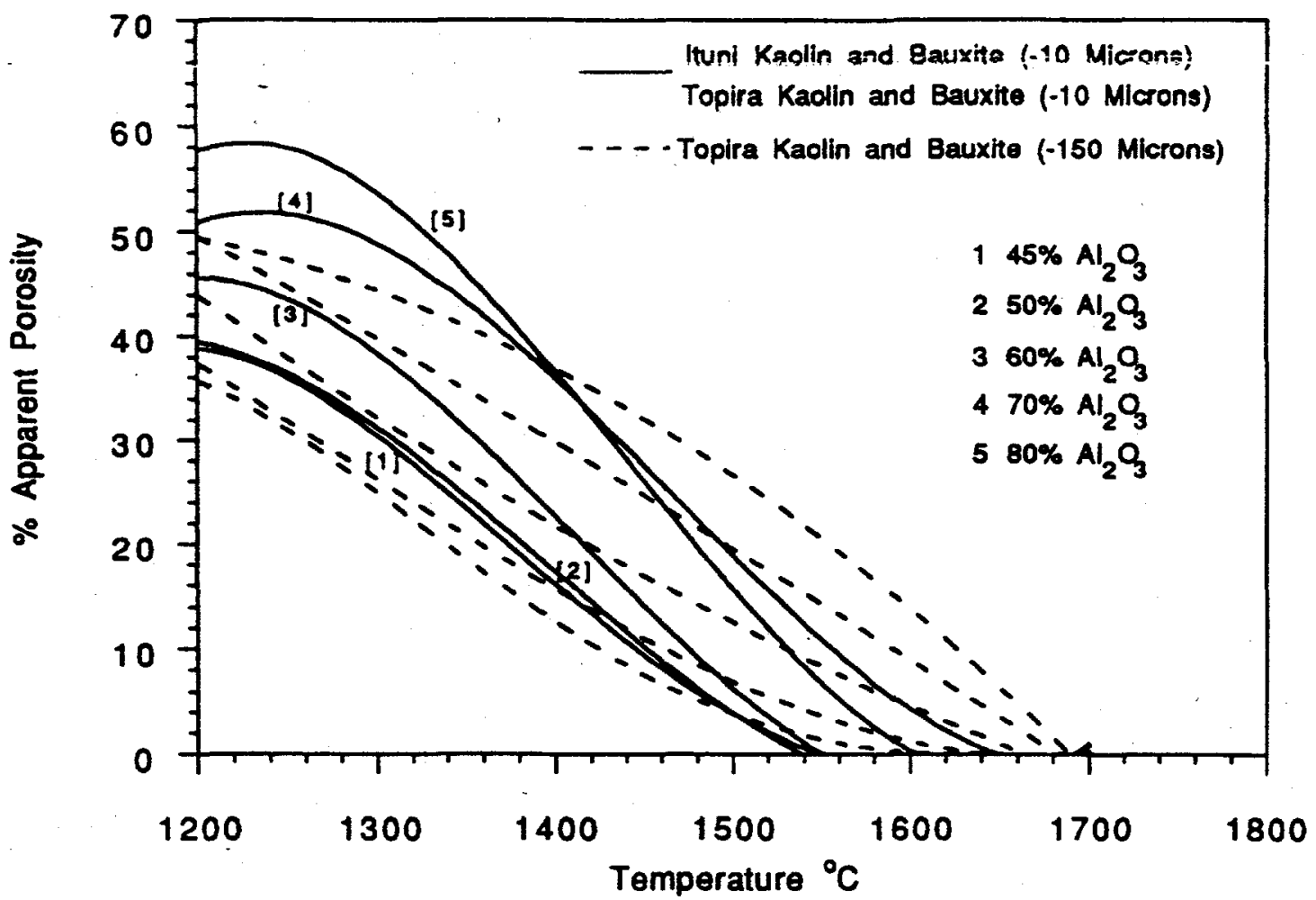

Figure 4 - The porosity of sintered kaolin/bauxite mixes at various conditions. 


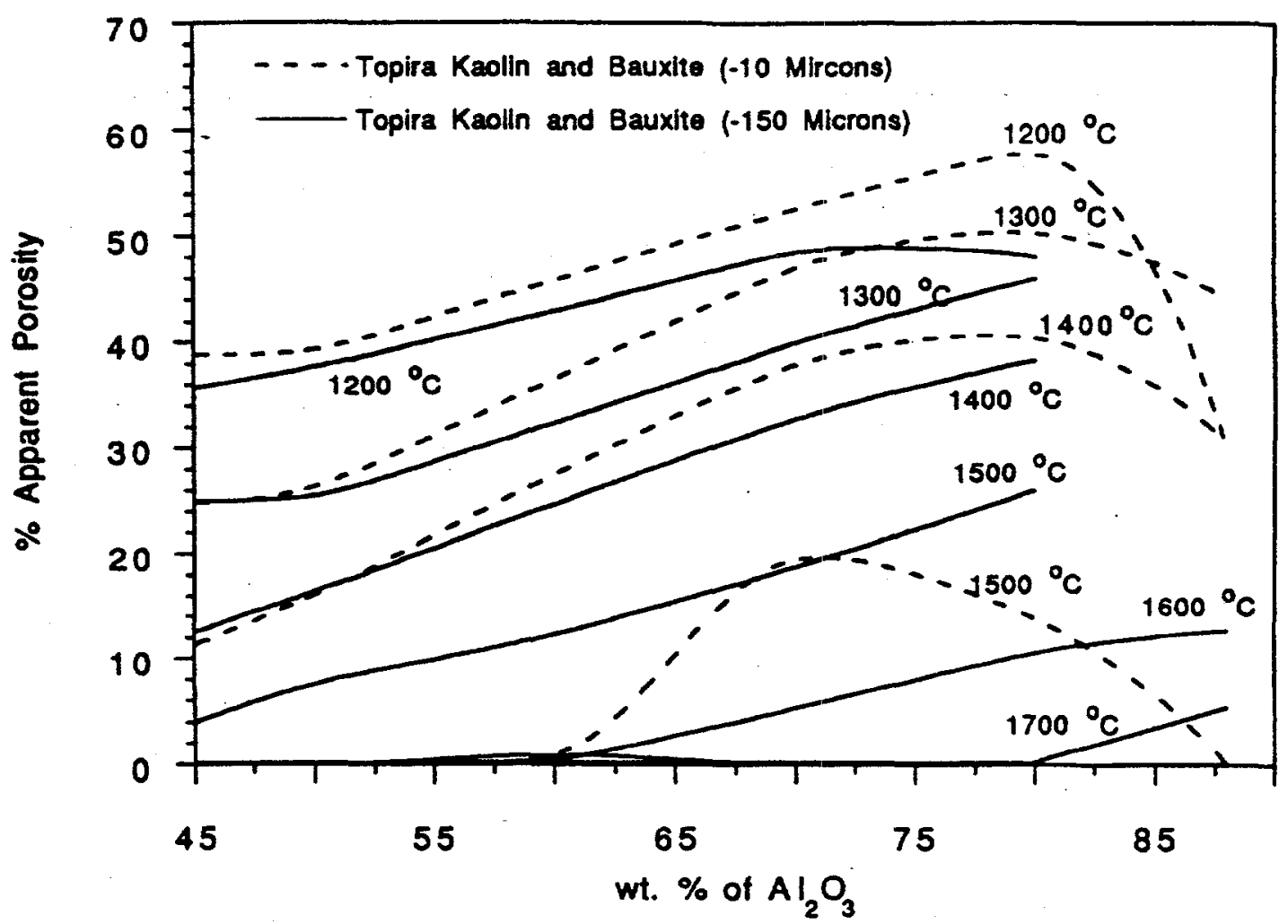

Figure 5 - The porosity of kaolin/bauxite mixes vs $\mathrm{Al}_{2} \mathrm{O}_{3}$ content. 


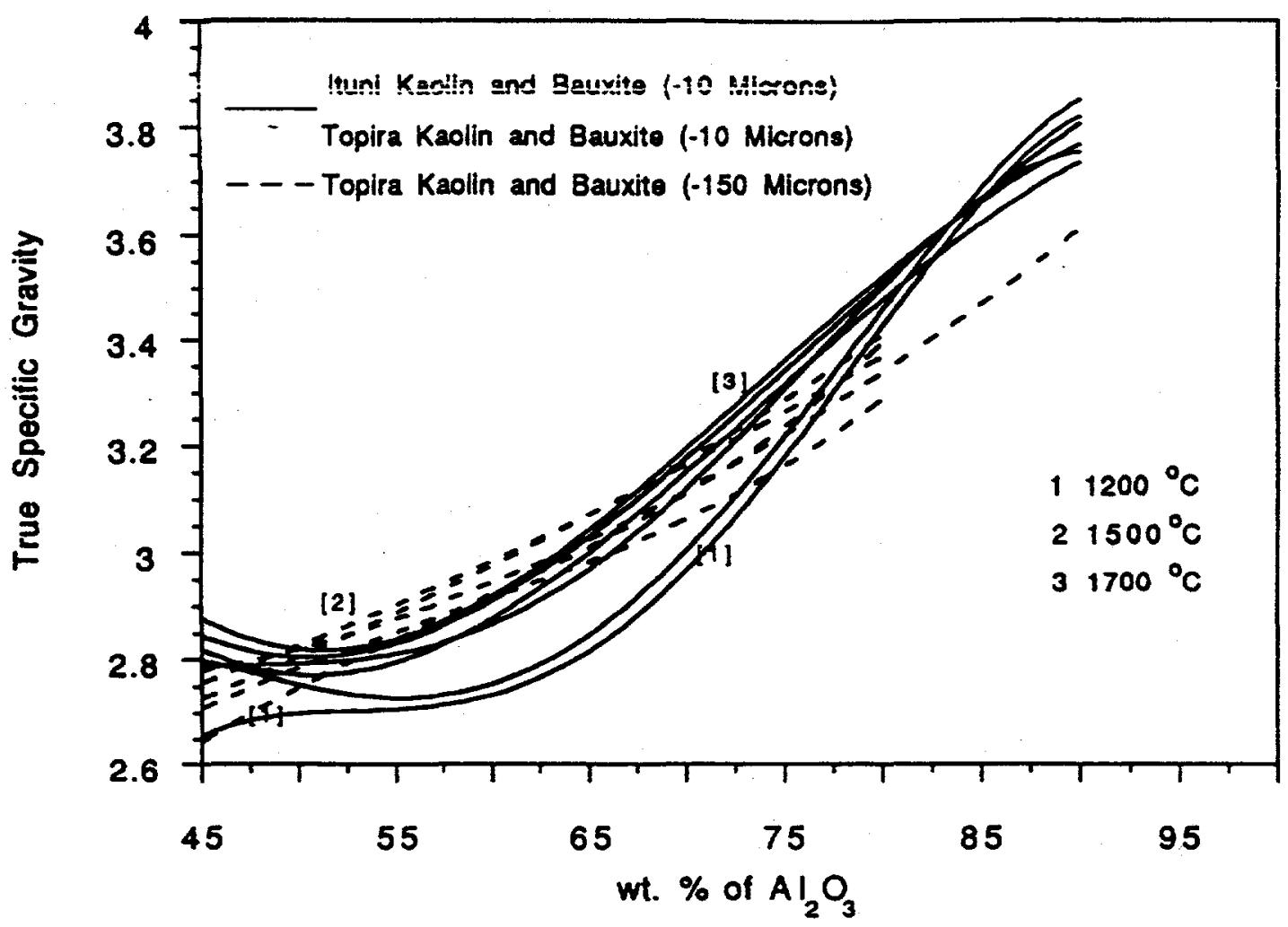

Figure 6 - The variation of true specific gravity of sintered kaolin/bauxite mixes with $\mathrm{Al}_{2} \mathrm{O}_{3}$ content. 


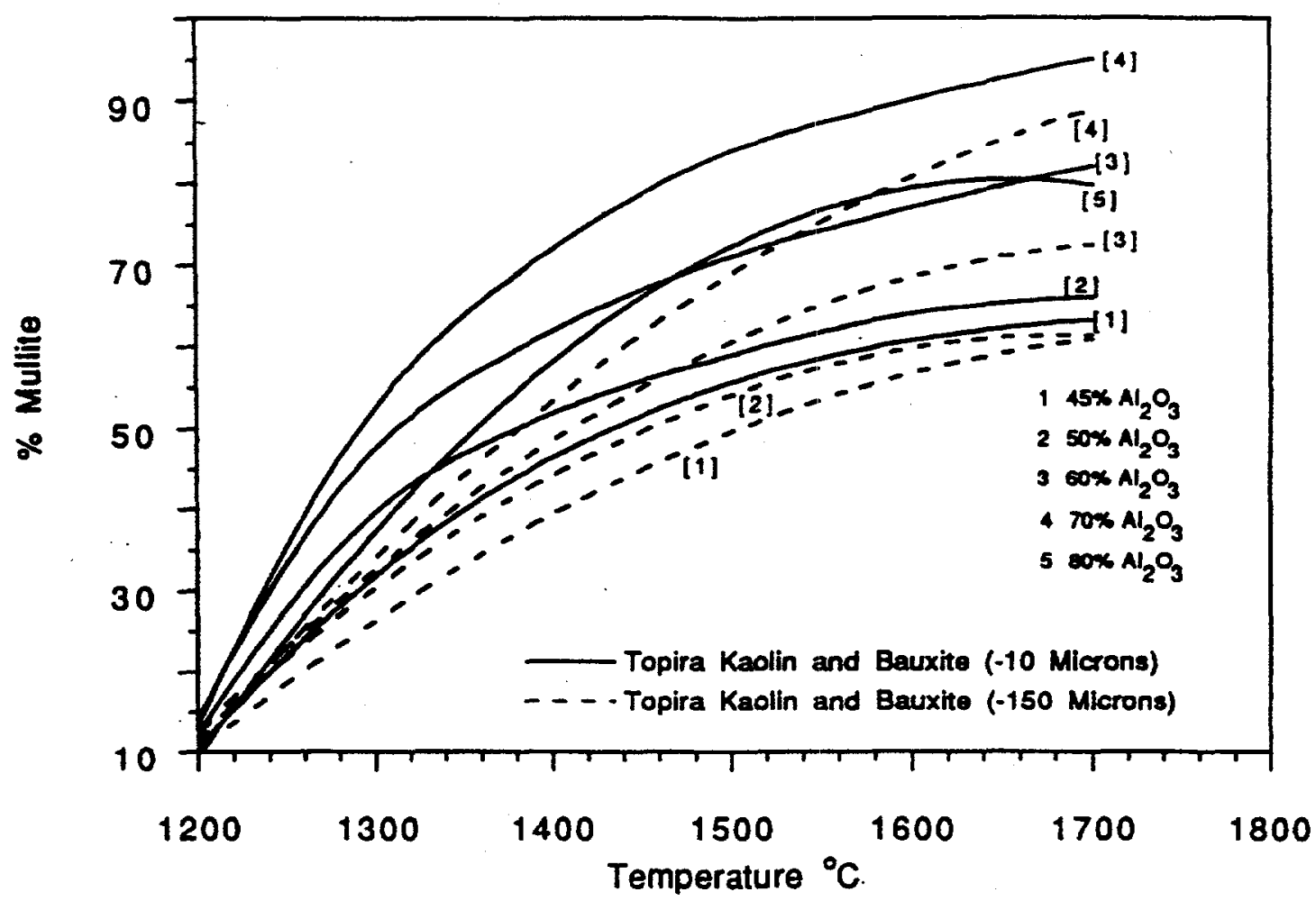

Figure 7 - The percentage of mullite phase vs sintering condition and $\mathrm{Al}_{2} \mathrm{O}_{3}$ content. 


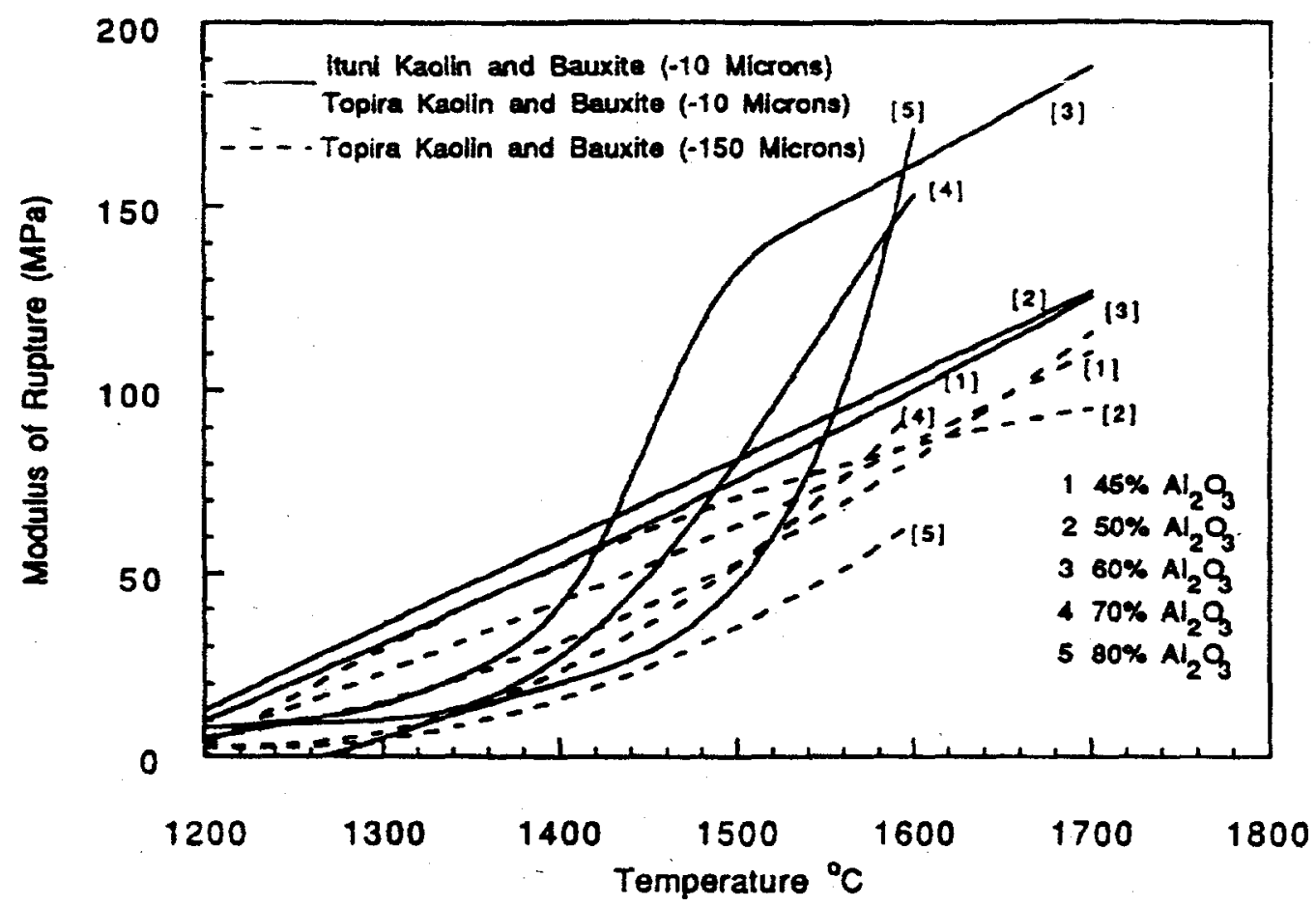

Figure 8 - The modulus of rupture for sintered kaolin/bauxite mixes at various conditions. 


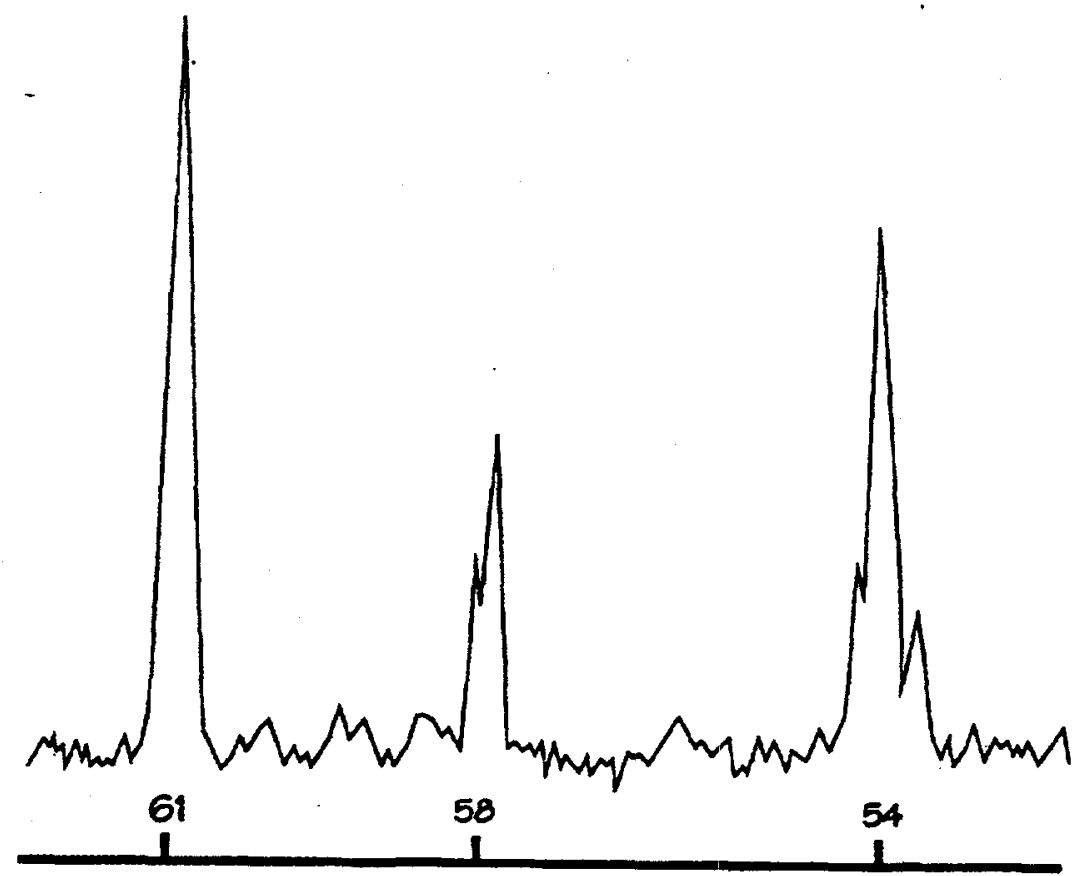

Figure 9 - The results of $x$-ray diffraction pattern analysis of a sintered mullite obtained commercially 

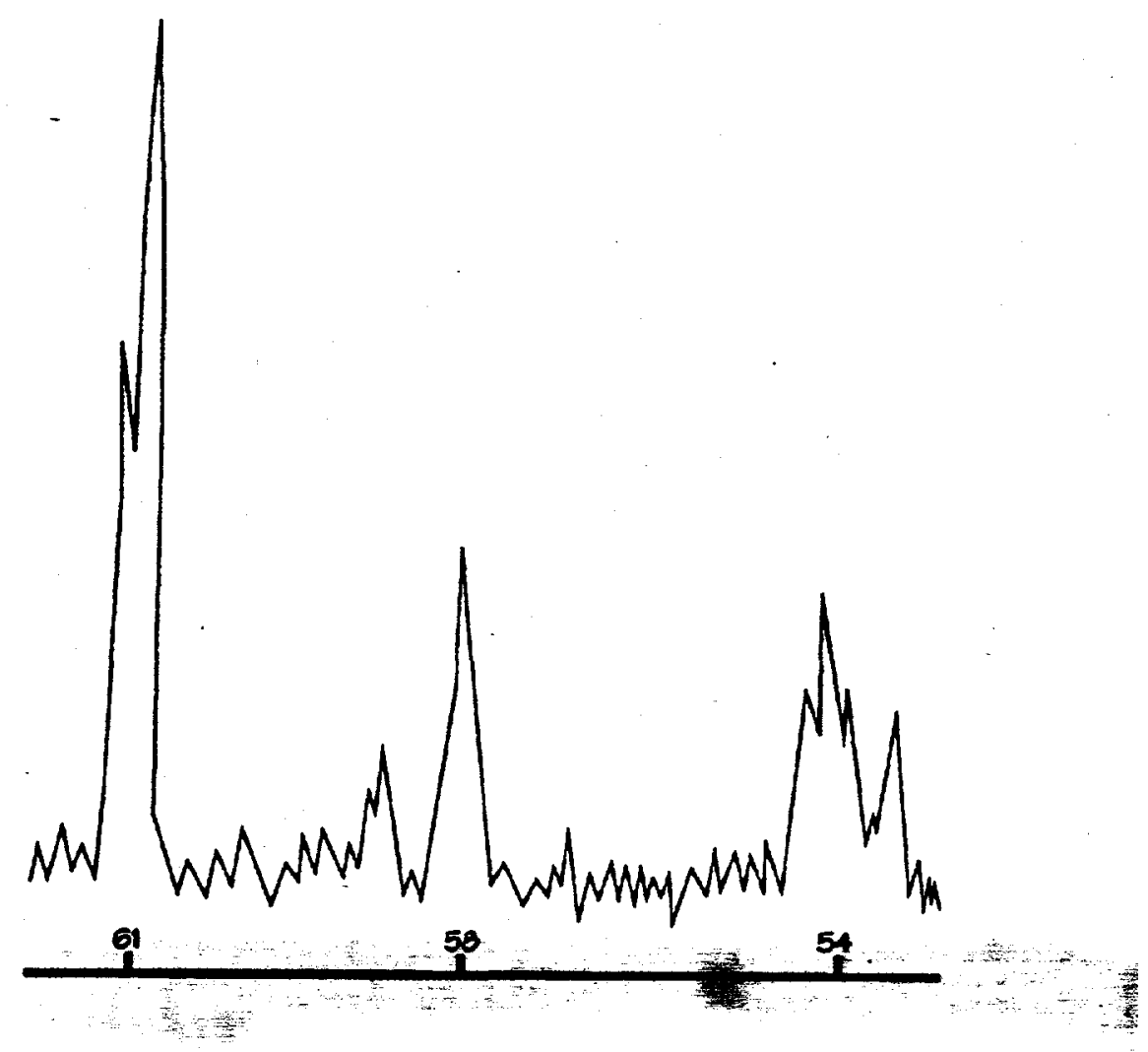

Figure 10 - The results of $x$-ray diflraction pattern of a kaolin/bauxite mix $(-10 \mu)$ dry-pressed and sintered at 1700 'c. 